\title{
Method of Evaluating Dynamic Accuracy of Five-axis Machine Tool Based on Test Piece and Comprehensive Evaluation System
}

\author{
Shijie Song, Xiaolin Dai, Xiaoning Li, and Dawei Gong* \\ School of Mechanical and Electrical Engineering, University of Electronic Science and Technology of China, \\ Chengdu 611731, China
}

(Received July 30, 2019; accepted November 5, 2019)

Keywords: dynamic accuracy, five-axis machine tool, evaluation method, $\mathrm{S}$ test piece, comprehensive evaluation system

To improve the dynamic accuracy of a five-axis machine tool, an evaluation method based on a test piece and a comprehensive evaluation (CE) system is proposed in this paper. The test pieces, namely, cone frustum and S test piece, in ISO 10791-7 are compared to show their ability to reflect the dynamic accuracy. After the comparison, the $\mathrm{S}$ test piece is selected owing to its various changes in contour error under different dynamic accuracies. The kinematic and dynamic simulation model is established to affect the effects of the various dynamic factors on the $\mathrm{S}$ test piece. The relationship between the dynamic factors and the $\mathrm{S}$ test piece is applied to the construction of a CE system. Then, the evaluation of the dynamic accuracy of the fiveaxis machine tool can be completed. On the basis of the evaluation result, the error is identified to determine the factors that must be adjusted. Thus, the dynamic accuracy of the fiveaxis machine tool can be improved by the adjustment. The proposed method is validated by experiments.

\section{Introduction}

The five-axis machine tool has become an indispensable part in the high-performance manufacturing industry nowadays owing to its advantages of better flexibility and working efficiency. It is widely applied in the machining of the parts with complex surfaces. The accuracy of the five-axis machine tool is always the focus of a user's attention. The static accuracy of the machine tool can be well evaluated and compensated before machining. However, the evaluation of the dynamic accuracy of the machine tool is much more difficult. ${ }^{(1)}$

The instrument and test piece are the two main tools for evaluating the machine tool accuracy. The common instruments for measurement include the laser interferometer, laser tracker, and double ball bar (DBB). These instruments are used on different occasions on the basis of their characteristics. The laser interferometer and laser tracker can achieve both direct and indirect measurements of geometric error. Several geometric error evaluation methods, such as the 22-, 14-, 9-, and 13-line methods, have been developed on the basis of the laser 
interferometer. ${ }^{(2-5)}$ Compared with the laser interferometer, the laser tracker can be used to track a moving target in real time. The multilateration method is very common in the laser tracker measurement, but multiple laser trackers are needed at the same time. ${ }^{(6,7)}$ As for a single laser tracker measurement, Aguado et al. studied the volumetric accuracy measurement of the machine tool. ${ }^{(8,9)}$ A DBB is widely used because it is convenient to use. Tsutsumi and Saito ${ }^{(10)}$ developed a set of measurement methods for measuring the geometric errors of a fiveaxis machine tool based on DBB, and their methods became a classic and have been always imitated. The measurement methods based on DBB mainly focus on the errors of rotary axes. ${ }^{(11,12)}$ However, the measurement error due to fixing multiple times is the shortage of DBB. In contrast, the R-test only needs one fixing and can achieve a rapid measurement. Ibaraki and coworkers have extensively studied a lot of research about the measurement of geometric errors based on the R-test. ${ }^{(13-15)}$ R-test has a good application prospect owing to its advantage of flexibility.

A test piece can reflect the accuracy of a machine tool through its contour errors and surface quality. For common test pieces, NAS979 test pieces are the most famous. ${ }^{(16)}$ The cone frustum in the NAS979 standard is specially designed to evaluate the five-axis machine tool, which is also adopted in ISO 10791-7..$^{(17)}$ On the basis of NAS979 test pieces, Matsushita et al. ${ }^{(18)}$ analyzed the effect of the workpiece positioning accuracy on the machining error of a five-axis machine tool. Hong et al. ${ }^{(19)}$ discussed the effect of various error motions of rotary axes on a five-axis machine tool on the machining geometric accuracy of the cone frustum. Some other test pieces were also designed in the application of the evaluation of the machine tool accuracy. Kiotoshi et al. ${ }^{(20)}$ used a truncated square pyramid to evaluate the accuracy of a five-axis machine tool. Ibaraki and coworkers proposed two test pieces to measure the geometric error of the five-axis machine tool. ${ }^{(21,22)}$ In the annex of ISO 10791-7, a new test piece called the S test piece is adopted. Wang et al. studied the geometric characteristics of the $\mathrm{S}$ test piece and then analyzed the effect of the machining error on the $\mathrm{S}$ test piece. ${ }^{(23,24)} \mathrm{Wu}$ et al. ${ }^{(25)}$ proposed a new iterative compensation methodology for the five-axis machine tool and used the $\mathrm{S}$ test piece to validate it. Zhong et al. ${ }^{(26)}$ applied the R-test to run the trajectory of the $\mathrm{S}$ test piece to evaluate the geometric and dynamic accuracy of the five-axis machine tool. As a new test piece adopted in ISO, the application of the $\mathrm{S}$ test piece to the evaluation of the accuracy of the fiveaxis machine tool still needs more in-depth research.

With the rapid development of machine tools, the machining error sources previously neglected are currently being reconsidered. The effect of dynamic accuracy on the final machining quality began to attract the attention of scholars. Poo et al. ${ }^{(27)}$ derived the expressions of the contour errors of straight lines and arcs by time domain analysis and analyzed the effect of servo parameters on the contour errors. Ramesh et al. ${ }^{(28)}$ highlighted the importance of considering the effect of the united movement of a multiaxis stage on contour errors based on Poo et al.'s work. On the basis of neural network control ${ }^{(29-31)}$ and gain control, ${ }^{(32)}$ Yang improved the dynamic performance of a robot. Sencer and Altintas ${ }^{(33)}$ employed a section of links to simulate the servo systems and then established a contour error model of a five-axis machine tool. They defined the contour error using the position offset and posture deviation of the tool cutter. Yang et al. ${ }^{(34)}$ developed the methods of identifing dynamic control parameters to better control robots. Yang and Altintas ${ }^{(35)}$ proposed an online 
evaluation and control method for the contour error of a five-axis machine tool. The contour error can be decreased by adjusting the servo parameters. From their work, it can be concluded that determining the relationship between the contour error and the servo parameters along with changing the servo parameters based on the relationship can help improve the dynamic accuracy of the machine tool.

Comprehensive evaluation (CE) is an evaluation method that is objective, reasonable, and comprehensive. Compared with the general evaluation method, the object of $\mathrm{CE}$ includes more attributes and requires more evaluation indicators. CE was first developed from decision theory and has been successfully applied to many other fields. ${ }^{(36,37)}$ If the object to be evaluated is regarded as a system, $\mathrm{CE}$ is used to evaluate the operating status of the system. Therefore, a $\mathrm{CE}$ system must be constructed to achieve the evaluation. The key parts of the CE system are the selection of the evaluation factors and the construction of the inside structure. To date, most research on CE is about the reasonable transfer of internal evaluation information. Yager and Filev ${ }^{(38)}$ proposed the ordered weighted average operator to evaluate the aggregation of information. On the basis of Yager and Filev's work, Xu and Da proposed a generalized ordered weighted average operator. ${ }^{(39)}$ Wang and Luo proposed the correlation coefficient and standard deviation integrated method to determine the attribute weight coefficient. ${ }^{(40)}$ With the improvement of the mathematical model, the evaluation effect of $\mathrm{CE}$ becomes better.

In this paper, we selected the $S$ test piece to evaluate the dynamic accuracy of a five-axis machine tool. The effects of various dynamic factors on the contour error of the $\mathrm{S}$ test piece were analyzed. Then, a CE system was constructed on the basis of the relationship between the $\mathrm{S}$ test piece and the dynamic accuracy of the five-axis machine tool. The evaluation can be achieved to help improve the dynamic accuracy of the five-axis machine tool. The structure of this paper is as follows. The kinematic and servo system model of the five-axis machine tool is described in Sect. 2. In Sect. 3, the cone frustum and S test piece are compared, and the effects of various dynamic factors on the contour error of S test piece are analyzed. In Sect. 4, the model and process of $\mathrm{CE}$ are described. The evaluation method proposed in this paper is validated in Sect. 5.

\section{Modeling of Five-axis Machine Tool}

\subsection{Kinematic model of the machine tool}

A five-axis machine tool with a tilting rotary table shown in Fig. 1 is used as the analysis target in this paper. The machine tool can be described as [ $\left.\begin{array}{llll}w & B & A & b\end{array} X^{\prime} t\right]$ by connecting the motion axes from the workpiece side to the tool cutter side; " $w$ " denotes the workpiece, " $b$ " denotes the bed, and " $t$ " denotes the tool cutter in this description.

The topological structure of this machine tool is shown in Fig. 2. Every moving part of the machine tool is marked with a number. The absolute coordinate system is fixed on the bed. The homogeneous transformation matrix (HTM) method is used to construct the kinematic relationship between the axes and the tool cutter. ${ }^{(41)}$ The transformation matrices between adjacent moving parts are listed in Table 1. Thus, the kinematic relationship can be expressed as in Eq. (1). 


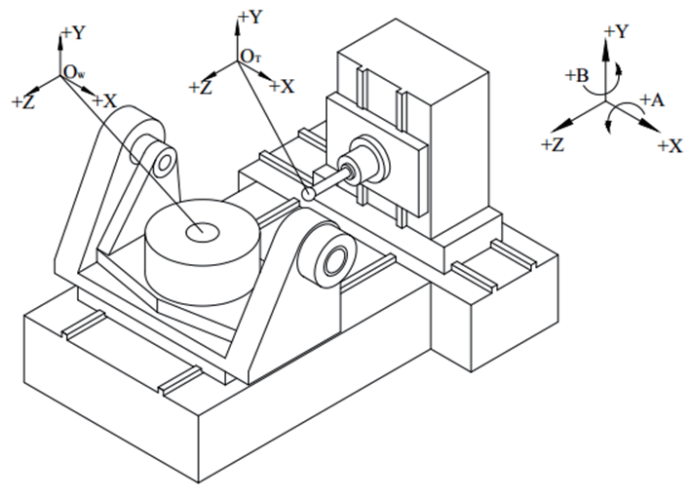

Fig. 1. Five-axis machine tool with tilting rotary table.

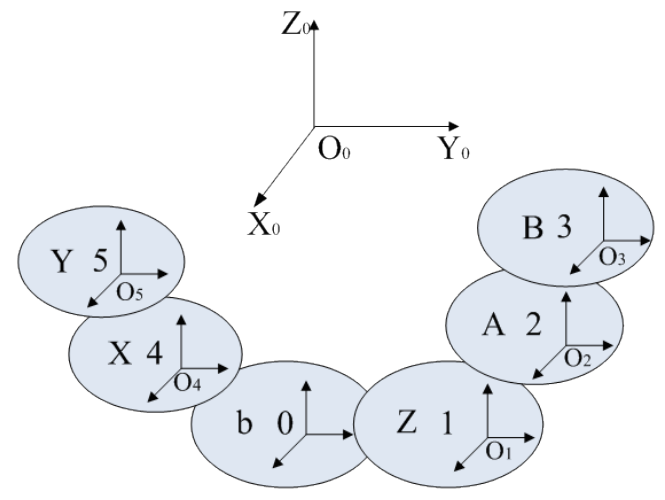

Fig. 2. (Color online) Topological structure of machine tool.

Table 1

Transformation matrices between adjacent parts.

\begin{tabular}{|c|c|c|c|c|c|c|c|c|c|c|c|c|c|c|c|}
\hline Workpiece side & & & $1-0$ & & & & & $2-1$ & & & & & & & \\
\hline & & & 0 & 0 & & & {$[1$} & 0 & 0 & 07 & & $\cos B$ & 0 & $\sin B$ & 07 \\
\hline Transformation & & & 1 & 0 & 0 & & 0 & $\cos A$ & $-\sin A$ & 0 & & 0 & 1 & 0 & 0 \\
\hline matrix between & $T_{10}=$ & ( & 0 & 1 & $Z$ & $T_{21}=$ & 0 & $\sin A$ & $\cos A$ & 0 & $T_{32}=$ & $-\sin B$ & 0 & $\cos B$ & 0 \\
\hline & & ( & 0 & 0 & 1 & & 0 & 0 & 0 & $1\rfloor$ & & 0 & 0 & 0 & $1]$ \\
\hline Tool side & & & $4-0$ & & & & & $5-4$ & & & & & & & \\
\hline & & & 0 & 0 & $X$ & & & {$\left[\begin{array}{ll}1 & 0\end{array}\right.$} & $\begin{array}{ll}0 & 0\end{array}$ & & & & & & \\
\hline Transformation & & 0 & 1 & 0 & 0 & & & $\begin{array}{ll}0 & 1\end{array}$ & $0 \quad Y$ & & & & & & \\
\hline matrix between & $T_{40}=$ & 0 & 0 & 1 & 0 & & $T_{54}=$ & $0 \quad 0$ & 1 & & & & & & \\
\hline & & 0 & 0 & 0 & 1 & & & & $0 \quad 1]$ & & & & & & \\
\hline
\end{tabular}

$$
P=\left(T_{32} T_{21} T_{10}\right)^{-1} T_{40} T_{54} P_{t}
$$

In Eq. (1), $P$ represents the position of the cutting point in the absolute coordinate system and $P_{t}$ represents the position of the cutting point in the tool coordinate system. If we assume that the length of the cutting tool is $L, P_{t}$ can be expressed as $[0,0,-L, 1]$ and $P$ can be expressed as $\left[X_{P}, Y_{P}, Z_{P}, 1\right]$. Thus, from Eq. (1), the kinematic equations can be expressed as

$$
\left\{\begin{array}{l}
X_{P}=X \cos B+L \cos A \sin B+Z \cos A \sin B \\
Y_{P}=Y \cos A-L \sin A-Z \sin A \\
Z_{P}=X \sin B-Z \cos A \cos B-Y \cos B \sin A-L \cos A \cos B .
\end{array}\right.
$$

\subsection{Model of servo systems}

For a five-axis machine tool, every axis has an independent servo and mechanical system. The system of the linear or rotary axis comprises the following parts: position control loop, 
velocity control loop, motor control loop, and mechanical structure. ${ }^{(42,43)}$ The schematic diagram of the system is shown in Fig. 3.

The mechanical structure of the linear axis is shown in Fig. 4. The dynamic equations of the axis movement can be expressed as Eq. (3). The definitions of the symbols are provided in Table 2.

$$
\left\{\begin{array}{l}
J_{m} \ddot{\theta}_{m}+c_{b} \dot{\theta}_{m}+f_{b}+\frac{l}{2 \pi} K\left(\frac{l}{2 \pi} \theta_{m}-x_{t}\right)+\frac{l}{2 \pi} c_{i}\left(\frac{l}{2 \pi} \dot{\theta}_{m}-\dot{x}_{t}\right)=T_{m} \\
M_{t} \ddot{x}_{t}+c_{t} \dot{x}_{t}+f_{t}=\frac{l}{2 \pi} K\left(\frac{l}{2 \pi} \theta_{m}-x_{t}\right)+\frac{l}{2 \pi} c_{i}\left(\frac{l}{2 \pi} \dot{\theta}_{m}-\dot{x}_{t}\right)
\end{array}\right.
$$

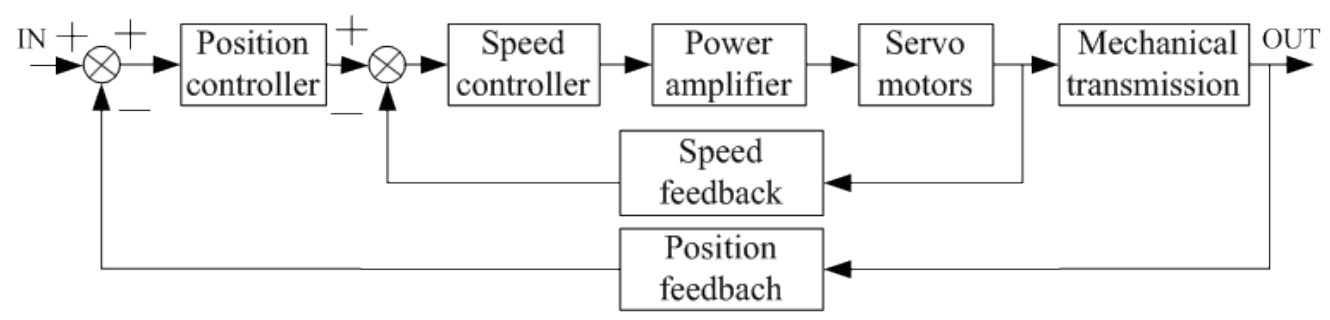

Fig. 3. Schematic diagram of servo system.

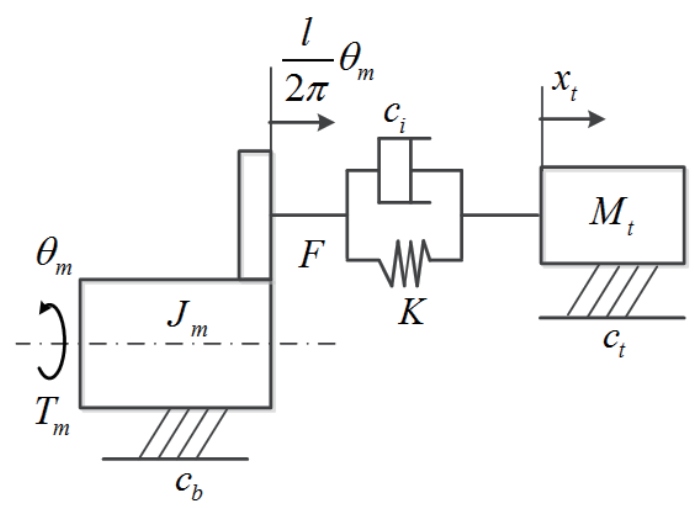

Fig. 4. Mechanical structure of linear axis.

Table 2

Definitions of symbols in dynamic equations of linear axis.

\begin{tabular}{|c|c|c|c|}
\hline Symbol & Physical meaning & Symbol & Physical meaning \\
\hline$J_{m}$ & Moment of inertia of motor & $T_{m}$ & Torque of motor \\
\hline$\theta_{m}$ & Rotation angle of motor & $c_{m}$ & Damping coefficient of motor \\
\hline$K$ & Equivalent axial stiffness & $c_{b}$ & Damping coefficient of ball screw \\
\hline$l$ & Screw lead & $f_{b}$ & Friction torque of ball screw \\
\hline$M_{t}$ & Equivalent mass of workbench & $x_{t}$ & Displacement of linear axis \\
\hline$c_{t}$ & Damping coefficient of guide & $f_{t}$ & Friction of guide \\
\hline
\end{tabular}


Combined with the controller of position and velocity, the whole servo system of the linear axis can be expressed as shown in Fig. 5.

Different from that of the linear axis, the output of the rotary axis is angular displacement. On the basis of the structure shown in Fig. 6, the dynamic equations of the axis movement can be expressed as Eq. (4). The definitions of the symbols are listed in Table 3.

$$
\left\{\begin{array}{l}
T=J_{m} \ddot{\theta}_{m}+c_{m} \dot{\theta}_{m}+R_{g} T_{g}+R_{g} c_{i g}\left(R_{g} \dot{\theta}_{m}-\dot{\theta}_{w}\right)+f_{m} \\
T_{g}=J_{w} \ddot{\theta}_{w}+c_{w} \dot{\theta}_{w}+R_{w} T_{w}+R_{w} c_{i w}\left(R_{w} \dot{\theta}_{w}-\dot{\theta}_{t}\right)+f_{w}-c_{i g}\left(R_{g} \dot{\theta}_{m}-\dot{\theta}_{w}\right) \\
T_{w}=J_{t} \ddot{\theta}_{t}+c_{t} \dot{\theta}_{t}+f_{t}-c_{i w}\left(R_{w} \dot{\theta}_{w}-\dot{\theta}_{t}\right)
\end{array}\right.
$$

As with the linear axis, the whole servo system of the rotary axis can be expressed as shown in Fig. 7.

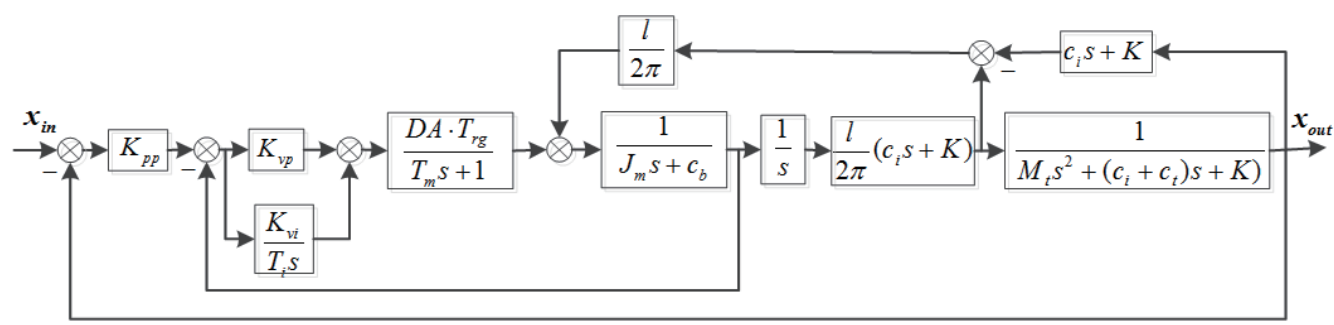

Fig. 5. Simulation model of servo system for linear axis.

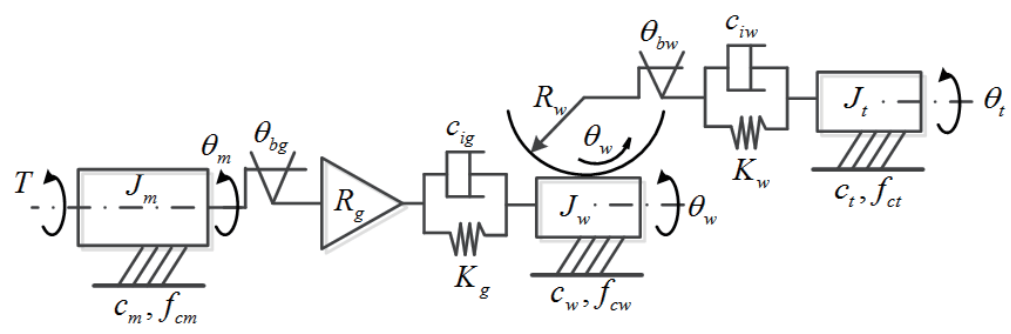

Fig. 6. Mechanical structure of rotary axis.

Table 3

Definitions of symbols in dynamic equations of rotary axis.

\begin{tabular}{|c|c|c|c|}
\hline Symbol & Physical meaning & Symbol & Physical meaning \\
\hline$J_{m}$ & Moment of inertia of motor & $\theta_{m}$ & Angular displacement of motor \\
\hline$C_{m}$ & Damping coefficient of motor & $R_{g}$ & Gear ratio \\
\hline$T_{g}$ & Output torque of gear transmission & $C_{i g}$ & $\begin{array}{l}\text { Damping coefficient between motor and gear } \\
\text { transmission }\end{array}$ \\
\hline$f_{m}$ & Friction torque of motor & $T_{m}$ & Output torque of motor \\
\hline$J_{w}$ & Moment of inertia of worm gear & $\theta_{w}$ & Angular displacement of worm gear \\
\hline$C_{w}$ & Damping coefficient of worm gear & $R_{w}$ & Worm gear ratio \\
\hline$C_{i w}$ & $\begin{array}{l}\text { Damping coefficient between workbench and } \\
\text { worm gear }\end{array}$ & $J_{t}$ & Moment of inertia of workbench \\
\hline$\theta_{t}$ & Angular displacement of workbench & $C_{t}$ & Damping coefficient of workbench \\
\hline$f_{t}$ & Friction torque of workbench & $T_{w}$ & Output torque of workbench \\
\hline
\end{tabular}




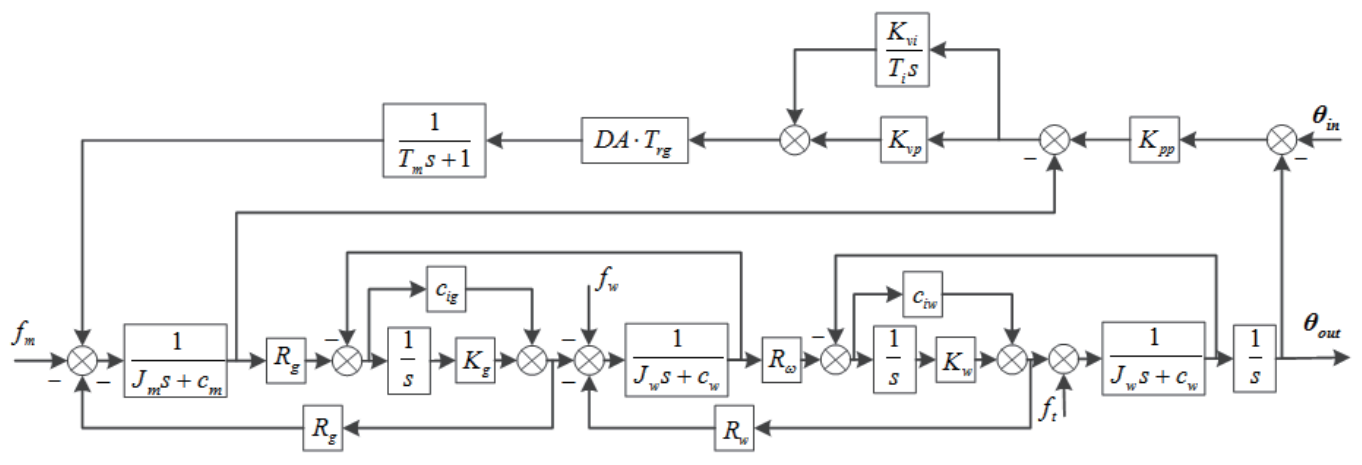

Fig. 7. Simulation model of servo system for rotary axis.

\section{Relationship Construction between S Test Piece and Dynamic Accuracy}

\subsection{Comparison of cone frustum and $S$ test piece}

As introduced in Sect. 1, the machine tool accuracy can be evaluated using both the instrument and the test piece. To combine with the application of CE, the test piece is selected to evaluate the machine tool dynamic accuracy in this paper. The cone frustum and $\mathrm{S}$ test piece are included in ISO 10791-7. The main geometric difference between the cone frustum and the $\mathrm{S}$ test piece is that the side surfaces of the $\mathrm{S}$ test piece are inextensible ruled surfaces. This difference leads to the twist of the side surfaces of the $S$ test piece, which results in the repeated reverse movements of the rotary axes. Taking the five-axis machine tool given in Sect. 2 as an example, we compared the axes' test piece movements. The simulation is carried out to compare these two test pieces. As shown in Fig. 8, the contour error can be simulated using the following several steps. First, the movement of each axis is determined from the inverse calculation of the NC post instruction. Then, the velocities of the axes are calculated using the S-shaped velocity control algorithm. ${ }^{(44)}$ Next, the practical trajectory of the tool's center position (TCP) is simulated through the combination of the servo system models and the kinematic model of the machine tool. Finally, the contour error can be obtained by comparing the practical trajectory with the theoretical one.

Through the S-shaped velocity control algorithm, the axes' velocities of the two test pieces can be obtained and are shown in Fig. 9. Similarly to the previous inference, the axes' velocities of the cone frustum are simpler, which can be described by Sine functions just like the axes' movements. In contrast, the axes' velocities of the $S$ test piece are more complex. As the dynamic accuracy is directly related to the velocity, the complex velocity of axes can better reflect the machine tool dynamic performance. Thus, the $\mathrm{S}$ test piece can better reflect the machine tool dynamic accuracy.

For a machine tool with a high dynamic accuracy, the dynamic performance of each axis should be consistent. The dynamic parameters of each axis should be set and adjusted synchronously. Thus, if the dynamic performance of an axis is abnormal, the contour error of the test piece is expected to be different. The following comparisons were made between 


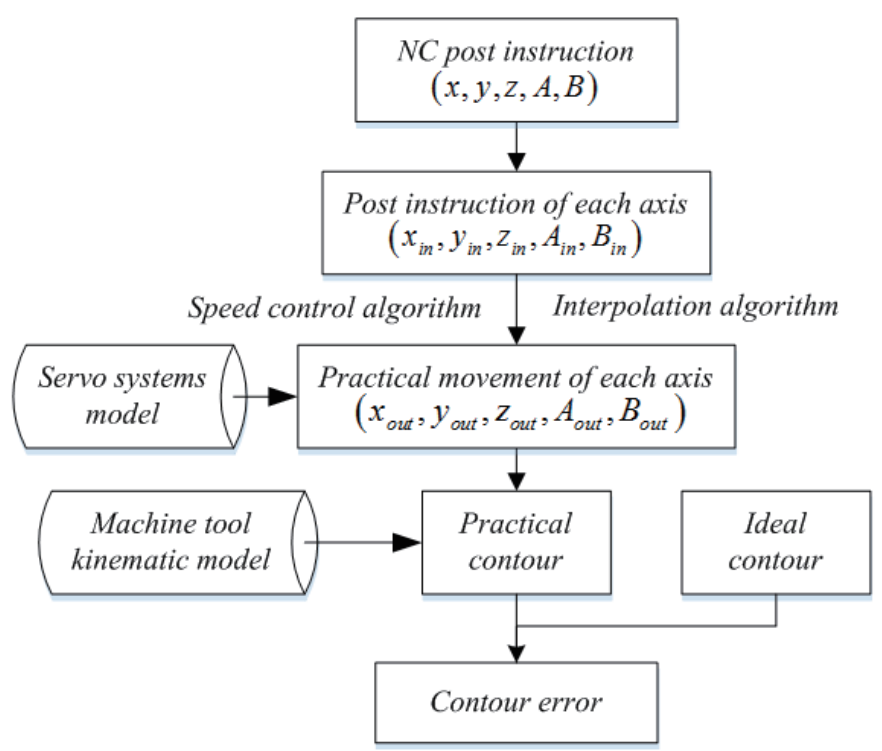

Fig. 8. Process of contour error simulation.

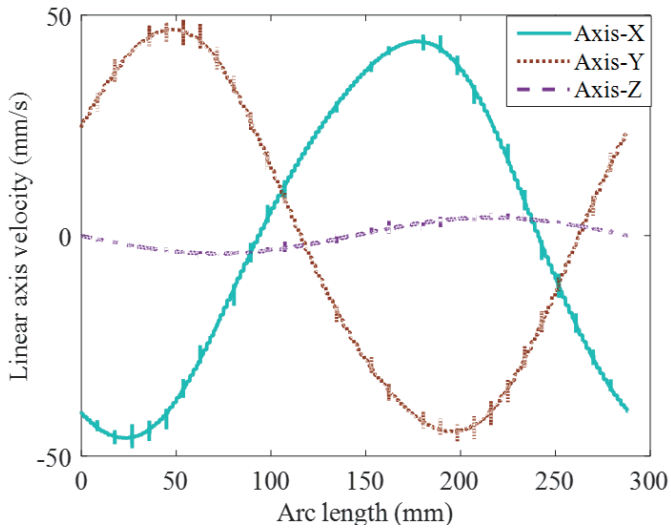

(a)

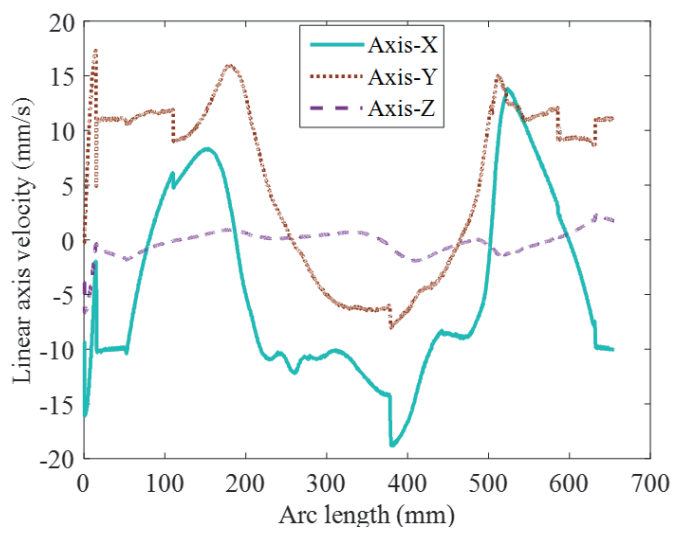

(c)

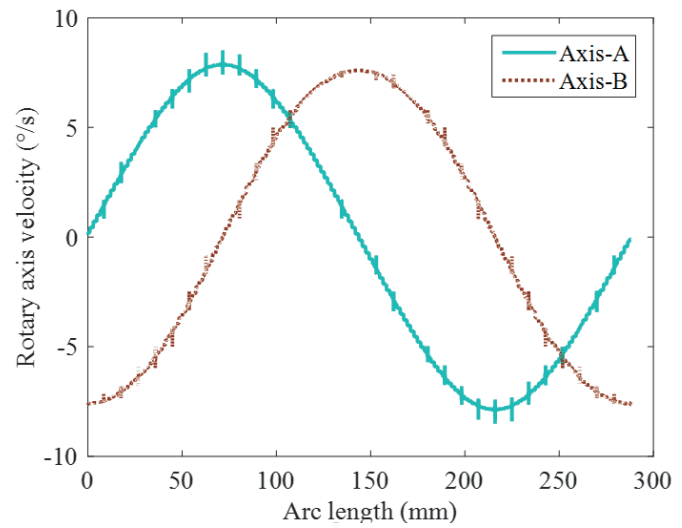

(b)

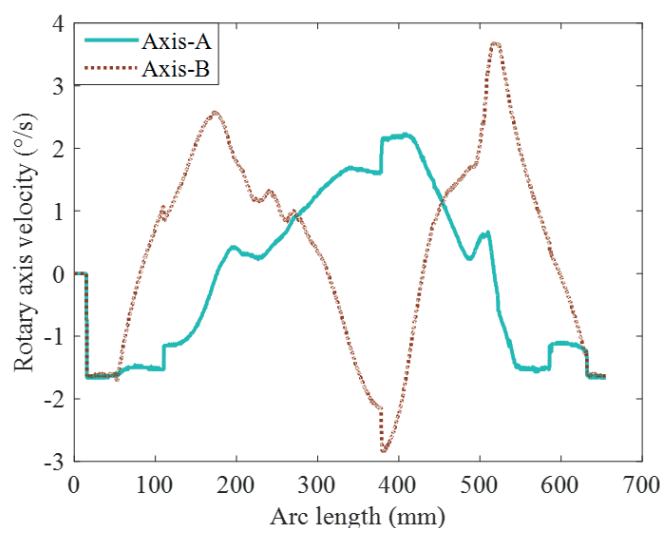

(d)

Fig. 9. (Color online) Comparison of axes' moving velocities between cone frustum and S test piece. (a) Linear axes' velocities of cone frustum. (b) Rotary axes' velocities of cone frustum. (c) Linear axes' velocities of S test piece. (d) Rotary axes' velocities of S test piece. 
the cone frustum and the $\mathrm{S}$ test piece to show their ability to reflect the machine tool dynamic accuracy. As shown in Fig. 10(a), when the position loop gain the $K_{p p}$ of the $X$-axis is set
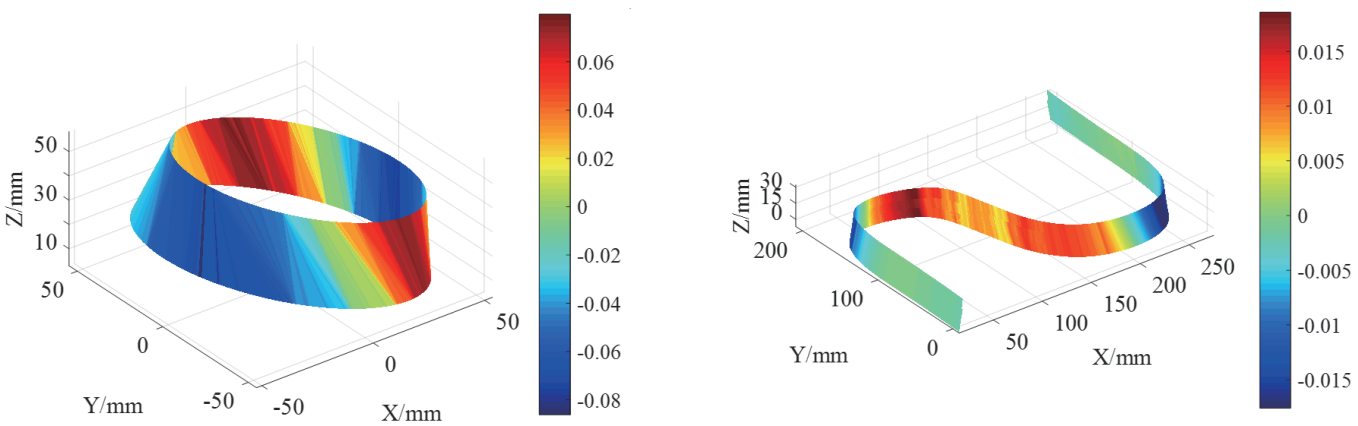

(a)
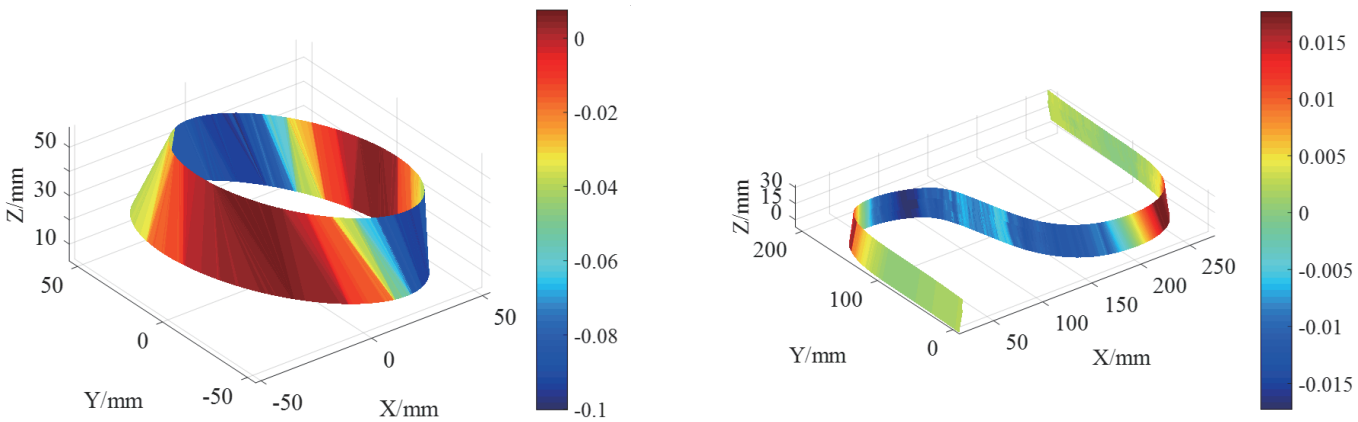

(b)
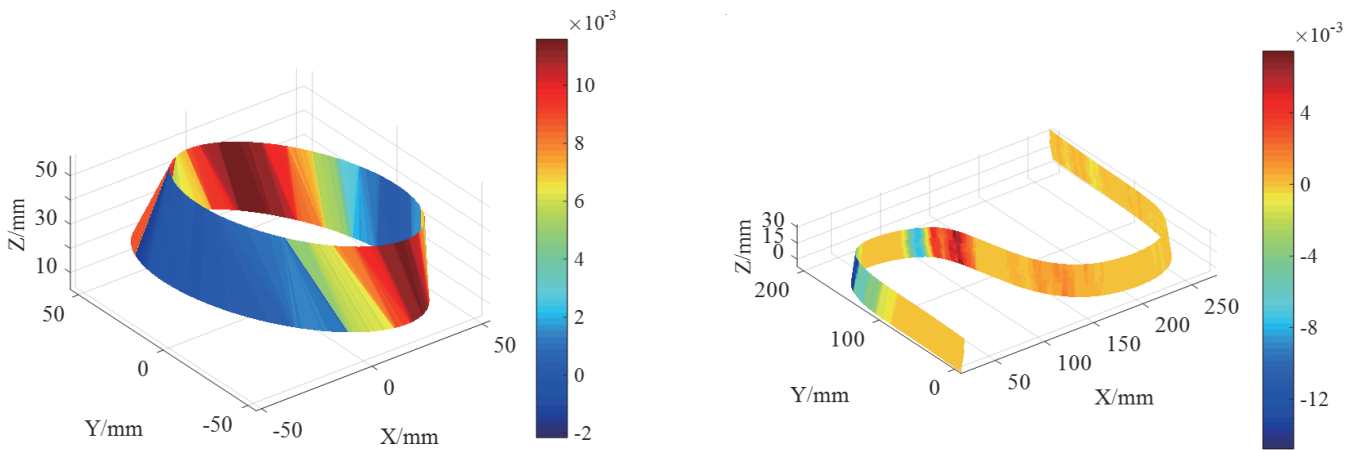

(c)
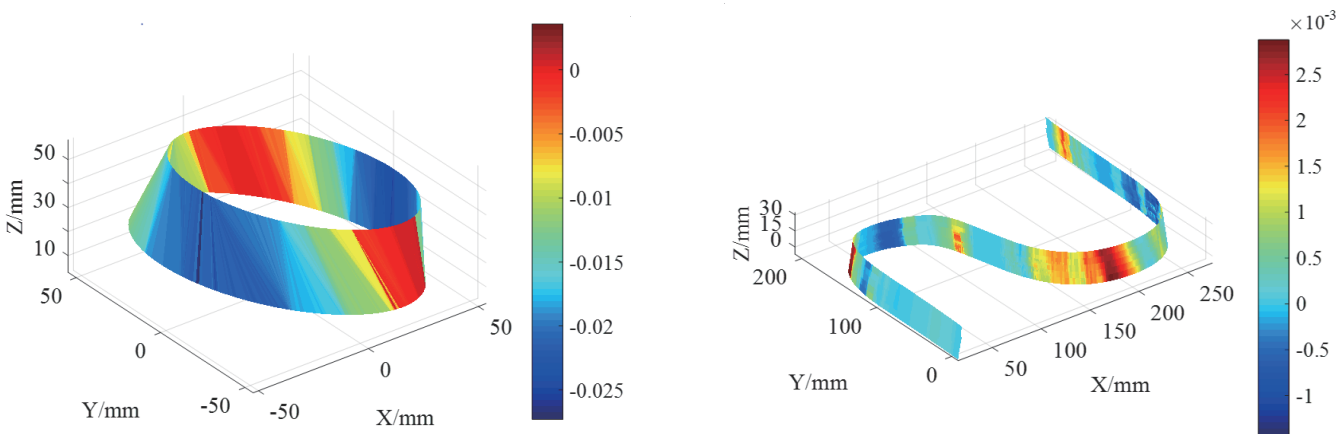

(d)

Fig. 10. (Color online) Cause of change in contour error of test piece when $K_{p p}$ 's of axes are set different. (a) The $K_{p p}$ of the $X$-axis is set different. (b) The $K_{p p}$ of the $Y$-axis is set different. (c) The $K_{p p}$ of the $A$-axis is set different. (d) The $K_{p p}$ of the $B$-axis is set different. 
different from those of the other axes intentionally, the cause of the change in the contour error of each test piece is displayed using chromatograms. In the same way, (b), (c), and (d) show the changes in contour error when the position loop gain of the $Y-, A-$, or $B$-axis is set different. Regardless of the magnitude of the contour error change, for the two test pieces, the locations of the contour error change are clearly different. For the cone frustum, the locations of the contour error change are nearly the same. The surface of the cone frustum can be divided into four areas only, and each area corresponds to a location with a significant change in contour error. However, for the $\mathrm{S}$ test piece, although the locations of the contour error change in (a) and (b) are nearly the same, the contour error change locations in (c) and (d) are markedly different. Compared with those of the cone frustum, the locations of the contour error change of the $\mathrm{S}$ test piece are diversified. The magnitude of the contour error change can be regarded as a quantitative difference, whereas the locations of the contour error change can be regarded as a qualitative difference. Clearly, for the contour error of each test piece, the qualitative difference can be better and easier to use than the quantitative difference to reflect the machine tool dynamic accuracy. Hence, the $\mathrm{S}$ test piece is selected to evaluate the machine tool dynamic accuracy.

\subsection{Relationship between machine tool dynamic parameters and contour error of $S$ test piece}

Some dynamic parameters are discussed in this section to determine how they affect the $\mathrm{S}$ test piece contour error. On the basis of the simulation model built above, the gain $K_{p p}$ of the position control loop, the gain $K_{v p}$, and the time constant $T_{i}$ of the velocity control loop are considered. In addition, the limits of acceleration and jerk speed and the backlash of each axis are also considered.

As the two side surfaces of the $\mathrm{S}$ test piece have analogous characteristics, one surface is chosen as the research target. The NC post instruction of the surface is the initial input of the contour error simulation. From the simulation results, the changes in machine tool dynamic accuracy have different effects on the $\mathrm{S}$ test piece contour error at different locations, and these changes are only reflected in particular areas. Thus, to better reflect the machine tool dynamic accuracy, the $\mathrm{S}$ test piece side surface is divided into nine zones. The division of the $\mathrm{S}$ test piece side surface is shown in Fig. 11, and the boundary coordinates are listed in Table 4.

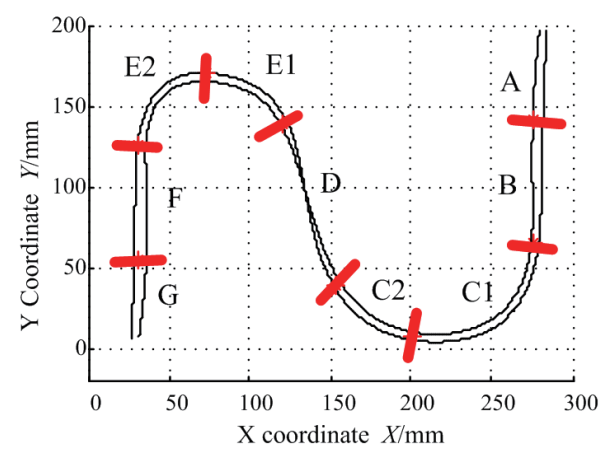

Fig. 11. (Color online) Nine zones of S test piece. 
Table 4

Coordinates of boundaries.

\begin{tabular}{lrrrrrrrr}
\hline Boundary $(\mathrm{mm})$ & $\mathrm{A} / \mathrm{B}$ & $\mathrm{B} / \mathrm{C} 1$ & $\mathrm{C} 1 / \mathrm{C} 2$ & $\mathrm{C} 2 / \mathrm{D}$ & $\mathrm{D} / \mathrm{E} 1$ & $\mathrm{E} 1 / \mathrm{E} 2$ & $\mathrm{E} 2 / \mathrm{F}$ & $\mathrm{F} / \mathrm{G}$ \\
\hline$X$ & 275.3 & 275.9 & 200.5 & 153.4 & 120.6 & 72.7 & 30.5 & 31.0 \\
$Y$ & 141.4 & 66.1 & 7.2 & 39.9 & 139.6 & 171.0 & 126.6 & 55.3 \\
\hline
\end{tabular}

The dynamic parameters may have much stronger effects on certain zones. As a result, these zones can better reflect the effects of the dynamic parameters and enable a better evaluation. For example, as shown in Fig. 11, when the $K_{p p}$ of the $X$-axis is decreased, the changes in contour error in zones $\mathrm{C}$ and $\mathrm{E}$ are much higher than those in the other zones. Similarly, zone E can better reflect the effect of the $K_{p p}$ of the $A$-axis. These zones are defined as the affected zones. Then, the simulations are made to determine the corresponding affected zones of the dynamic parameters; the simulation results are listed in Tables 5-9. In the simulation, $K_{v p}$ and $T_{i}$ are adjusted together to examine the change in contour error because they belong to the same velocity control loop. The A/B in the tables represents the boundary between zones A and $\mathrm{B}$. The other matching symbols have similar meanings. When the effects of the dynamic parameters on the contour error are very small, no affected zones exist.

\section{Evaluation of Five-axis Machine Tool Dynamic Performance}

The relationship between the machine tool dynamic parameters and the contour error of the $\mathrm{S}$ test piece is established in Sect. 3. Different dynamic factors have their own affected zones. This relationship is progressive by layers. As a result, to better use this relationship to evaluate the machine tool dynamic accuracy, an evaluation system with a multilayer structure should be adopted. The CE system can accomplish this task and is selected for evaluation in this paper. In this section, the machine tool dynamic accuracy evaluation is described.

\subsection{Modelling of CE system}

In this part, $\mathrm{CE}$ is adopted to build the evaluation model. The key parts of $\mathrm{CE}$ are the selection of the evaluation factors and the construction of the inside structure. The selection of the evaluation factors is based on the target of evaluation. These independent factors should have a direct impact on the target and should be very representative. The construction of the inside structure mainly involves the relationships of the structure of each layer and the determinations of the weight coefficients. The machine tool dynamic accuracy is set as the evaluation target, and the dynamic parameters are set as the evaluation factors. The relationship between the contour error of the $\mathrm{S}$ test piece and the dynamic parameters is used to construct the inside structure of CE.

(1) Model of the inside structure of CE

Five-axis machine tools have 3 linear axes and 2 rotary axes. Each axis is controlled by its own dynamic parameters. The dynamic parameters are expected to affect the contour error of the $\mathrm{S}$ test piece in different zones with different values. On the basis of this relationship, the inside structure of CE can be constructed as shown in Fig. 12. The details of the inside 
Table 5

Effects of dynamic parameters of $X$-axis on zones.

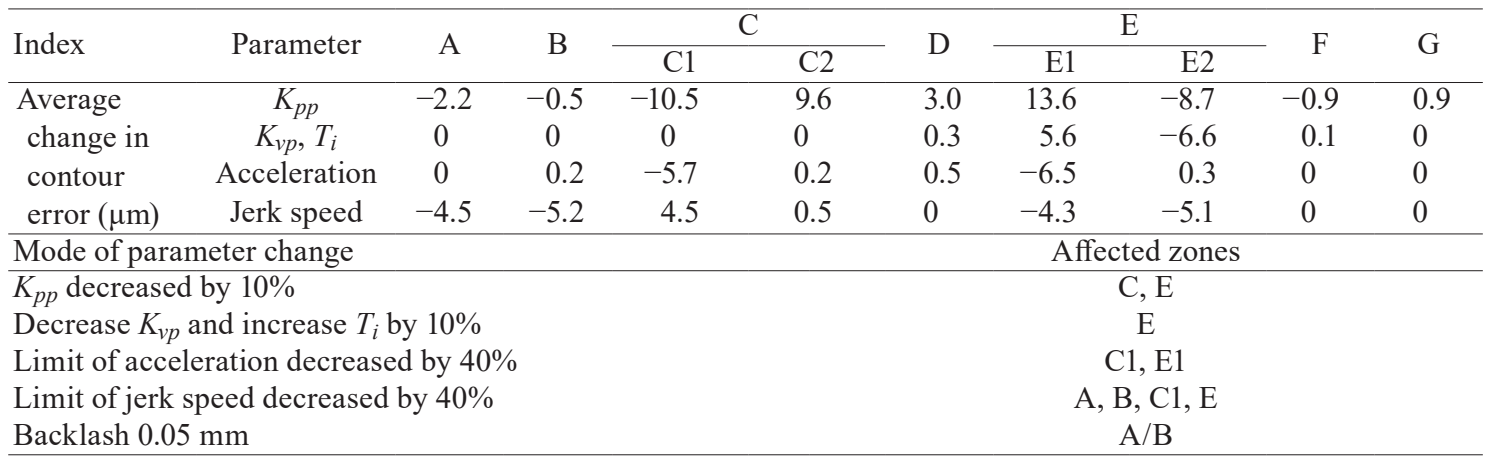

Table 6

Effects of dynamic parameters of $Y$-axis on zones.

\begin{tabular}{|c|c|c|c|c|c|c|c|c|c|c|}
\hline \multirow{2}{*}{ Index } & \multirow{2}{*}{ Parameter } & \multirow{2}{*}{ A } & \multirow{2}{*}{ B } & \multicolumn{2}{|c|}{$\mathrm{C}$} & \multirow{2}{*}{ D } & \multicolumn{2}{|c|}{$\mathrm{E}$} & \multirow{2}{*}{$\mathrm{F}$} & \multirow{2}{*}{ G } \\
\hline & & & & $\mathrm{C} 1$ & $\mathrm{C} 2$ & & E1 & E2 & & \\
\hline Average & $K_{p p}$ & 2.2 & 0.5 & 9.5 & -8.6 & 3.0 & -8.6 & 9.7 & 0.9 & 0.9 \\
\hline change in & $K_{v p}, T_{i}$ & 0 & 0 & 0 & 0 & 0 & 0.2 & -0.2 & 0 & 0 \\
\hline contour error & Acceleration & 0 & 0 & -3.7 & 0 & 0 & -3.6 & 0 & 0 & 0 \\
\hline$(\mu \mathrm{m})$ & Jerk speed & -3.5 & -3.2 & 4.5 & 0.5 & 0 & -4.3 & -5.1 & 0 & 0 \\
\hline
\end{tabular}

Mode of parameter change

$K_{p p}$ decreased by $10 \%$

Affected zones

Decrease $K_{v p}$ and increase $T_{i}$ by $10 \%$

C, E

Limit of acceleration decreased by $40 \%$

Limit of jerk speed decreased by $40 \%$

$\mathrm{A}, \mathrm{B}, \mathrm{C} 1, \mathrm{E}$

Backlash $0.05 \mathrm{~mm}$

Table 7

Effects of dynamic parameters of $Z$-axis on zones.

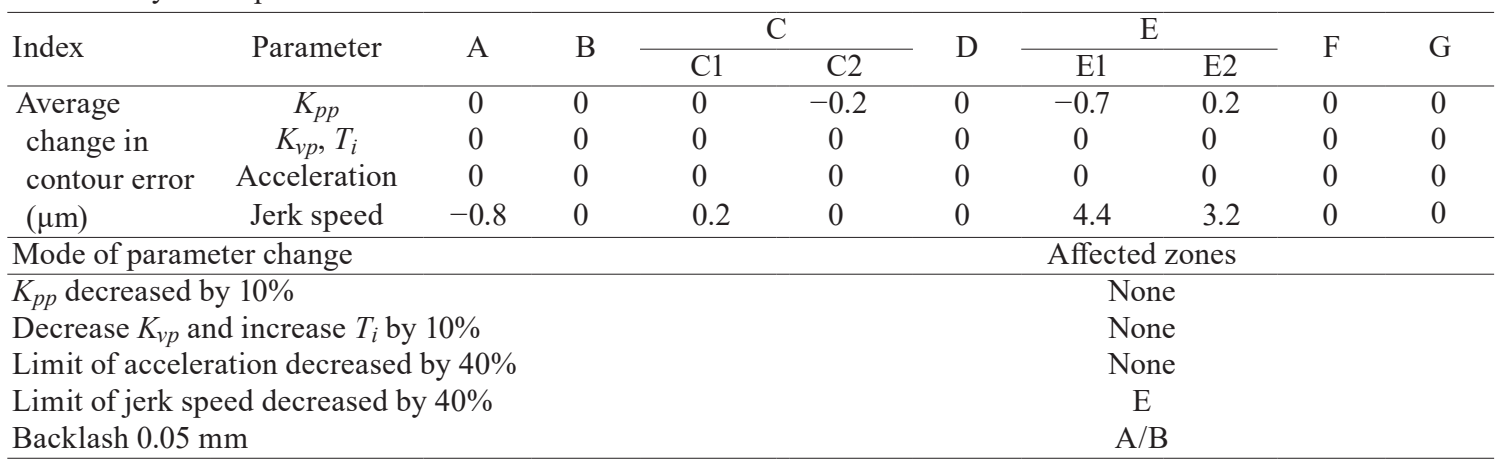

Table 8

Effects of dynamic parameters of $A$-axis on zones.

\begin{tabular}{|c|c|c|c|c|c|c|c|c|c|c|}
\hline \multirow{2}{*}{ Index } & \multirow{2}{*}{ Parameter } & \multirow{2}{*}{ A } & \multirow{2}{*}{ B } & \multicolumn{2}{|c|}{$\mathrm{C}$} & \multirow{2}{*}{$\mathrm{D}$} & \multicolumn{2}{|c|}{$\mathrm{E}$} & \multirow{2}{*}{$\mathrm{F}$} & \multirow{2}{*}{ G } \\
\hline & & & & $\mathrm{C} 1$ & $\mathrm{C} 2$ & & E1 & E2 & & \\
\hline \multirow{4}{*}{$\begin{array}{l}\text { Average } \\
\text { change in } \\
\text { contour error } \\
(\mu \mathrm{m})\end{array}$} & $K_{p p}$ & 0.2 & 0 & 0 & 0.6 & 1.0 & 5.2 & -6.7 & -5.6 & 0.1 \\
\hline & $K_{v p}, T_{i}$ & -3.7 & 0.2 & 4.5 & 3.6 & 0 & 5.1 & -3.3 & 0.2 & 0 \\
\hline & Acceleration & 4.4 & -5.6 & 4.2 & 5.9 & 0 & 6.2 & -4.1 & 0 & 0 \\
\hline & Jerk speed & -3.7 & 0 & 0.3 & 0.4 & 0 & -3.2 & -4.1 & 0.1 & 0 \\
\hline \multicolumn{5}{|c|}{ Mode of parameter change } & \multicolumn{6}{|c|}{ Affected zones } \\
\hline \multicolumn{5}{|c|}{$K_{p p}$ decreased by $10 \%$} & \multicolumn{6}{|c|}{$\mathrm{E}$} \\
\hline \multicolumn{5}{|c|}{ Decrease $K_{v p}$ and increase $T_{i}$ by $10 \%$} & \multicolumn{6}{|c|}{$\mathrm{A}, \mathrm{C}, \mathrm{E}$} \\
\hline \multicolumn{5}{|c|}{ Limit of acceleration decreased by $40 \%$} & \multicolumn{6}{|c|}{$\mathrm{A}, \mathrm{B}, \mathrm{C}, \mathrm{E}$} \\
\hline \multicolumn{5}{|c|}{ Limit of jerk speed decreased by $40 \%$} & \multicolumn{6}{|c|}{ A, E } \\
\hline \multicolumn{4}{|c|}{ Backlash $0.05 \mathrm{~mm}$} & & \multicolumn{6}{|c|}{ E1/E2 } \\
\hline
\end{tabular}


Table 9

Effects of dynamic parameters of $B$-axis on zones.

\begin{tabular}{|c|c|c|c|c|c|c|c|c|c|c|}
\hline \multirow{2}{*}{ Index } & \multirow{2}{*}{ Parameter } & \multirow{2}{*}{ A } & \multirow{2}{*}{ B } & \multicolumn{2}{|c|}{$\mathrm{C}$} & \multirow{2}{*}{$\mathrm{D}$} & \multicolumn{2}{|c|}{$\mathrm{E}$} & \multirow{2}{*}{ F } & \multirow{2}{*}{$\mathrm{G}$} \\
\hline & & & & $\mathrm{Cl}$ & $\mathrm{C} 2$ & & E1 & E2 & & \\
\hline \multirow{4}{*}{$\begin{array}{l}\text { Average } \\
\text { change in } \\
\text { contour error } \\
(\mu \mathrm{m})\end{array}$} & $K_{p p}$ & 4.2 & -5.6 & 0.1 & 5.2 & 0.1 & -0.1 & 7.5 & 0.1 & 0.1 \\
\hline & $K_{v p}, T_{i}$ & 0 & 0 & 4.3 & 6.1 & 0 & 4.8 & -0.2 & 0 & 0 \\
\hline & Acceleration & 4.2 & -4.6 & 3.4 & 4.2 & 0 & 5.3 & -3.9 & 0 & 0 \\
\hline & Jerk speed & 0.3 & 0 & 0.1 & 0.3 & 0.1 & 4.1 & 0.2 & 0 & 0.1 \\
\hline \multicolumn{5}{|c|}{ Mode of parameter change } & \multicolumn{6}{|c|}{ Affected zones } \\
\hline \multicolumn{5}{|c|}{$K_{p p}$ decreased by $10 \%$} & \multicolumn{6}{|c|}{$\mathrm{A}, \mathrm{B}, \mathrm{C} 2, \mathrm{E} 2$} \\
\hline \multicolumn{5}{|c|}{ Decrease $K_{v p}$ and increase $T_{i}$ by $10 \%$} & \multicolumn{6}{|c|}{$\mathrm{C}, \mathrm{E} 1$} \\
\hline \multicolumn{5}{|c|}{ Limit of acceleration decreased by $40 \%$} & \multicolumn{6}{|c|}{$\mathrm{A}, \mathrm{B}, \mathrm{C}, \mathrm{E}$} \\
\hline \multicolumn{5}{|c|}{ Limit of jerk speed decreased by $40 \%$} & \multicolumn{6}{|c|}{ E1 } \\
\hline \multicolumn{5}{|c|}{ Backlash $0.05 \mathrm{~mm}$} & \multicolumn{6}{|c|}{$\mathrm{A} / \mathrm{B}, \mathrm{B} / \mathrm{C} 1, \mathrm{C} 1 / \mathrm{C} 2, \mathrm{E} 1 / \mathrm{E} 2, \mathrm{E} 2 / \mathrm{F}$} \\
\hline
\end{tabular}

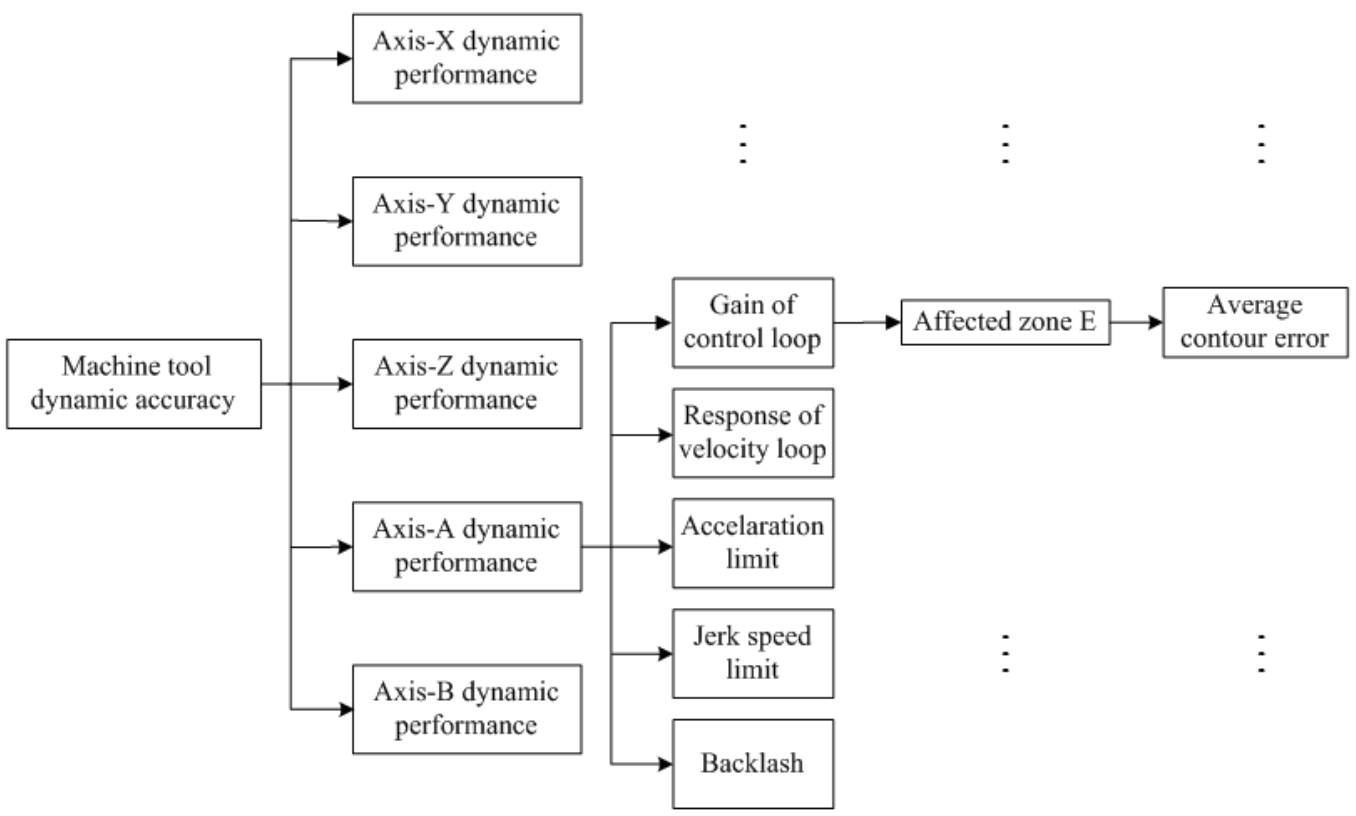

Fig. 12. Inside structure of CE.

structure of $\mathrm{CE}$ are omitted; however, they can be inferred from the details shown for the $A$-axis. Five parameters are chosen to reflect the dynamic performance of each axis. Each parameter has its own affected zones. Regarding the gain of the control loop of the $A$-axis, its affected zone is $\mathrm{E}$ according to the simulation results. To determine the weight coefficients, the average contour error of the zones is considered.

(2) Calculation of parameters in $\mathrm{CE}$

a. Membership function

As shown in Fig. 12, the inside structure of CE consists of 5 layers. Membership functions are applied to describe the relationships between the layers. Thus, by the recursive calculation of the memberships from the bottom layer to the top layer, the evaluation result of the machine tool dynamic accuracy can be obtained. From the simulation results, the 
distribution of the contour error of the $\mathrm{S}$ test piece belongs to the center membership functions, so the corresponding ridge distribution function is selected as the membership function. The expression of the ridge function is given by Eq. (5). The values of $a, b$, and $c$ in the equation are determined on the basis of the data used to calculate the membership function.

$$
f(x)= \begin{cases}0 & x \leq a \\ 0.5+0.5 \sin \frac{\pi}{b-a}\left(x+\frac{a+b}{2}\right) \quad a<x \leq b \\ 1 \quad b<x \leq 2 c-b \\ 0.5+0.5 \sin \frac{\pi}{b-a}\left(x-\frac{4 c-a-b}{2}\right) \quad 2 c-b<x \leq 2 c-a \\ 0 \quad x \geq 2 c-a\end{cases}
$$

Taking the average contour error as an example, we constructed its membership function using the simulation results, as shown in Fig. 13. There are five ridge distribution functions in Fig. 13, and each function corresponds to a layer in CE.

\section{b. Calculations of weights}

The weights are very important in CE, as they directly affect the evaluation of the target. In this paper, the correlation of each factor is low, and the error cause identification should focus on the effect level of each factor; thus, the weights are calculated by the entropy method. The more information that a factor occupies, the smaller its entropy is, and the greater its weight will be. In $\mathrm{CE}$, assuming that the numbers of evaluation factors and objects are $\mathrm{m}$ and $\mathrm{n}$, respectively, the initial data matrix is $X=\left(x_{i j}\right)_{m \times n}$. If $x_{i j}$ for the factor $i$ differs much more from the others, it will have a large effect on CE. The calculations of the weights by the entropy method consist of three steps. First, the initial data matrix $X$ should be standardized to $R$. The value of $r_{i j}$ in the matrix $R$ represents the standard value of the $i$ th factor of the $j$ th object, as described by

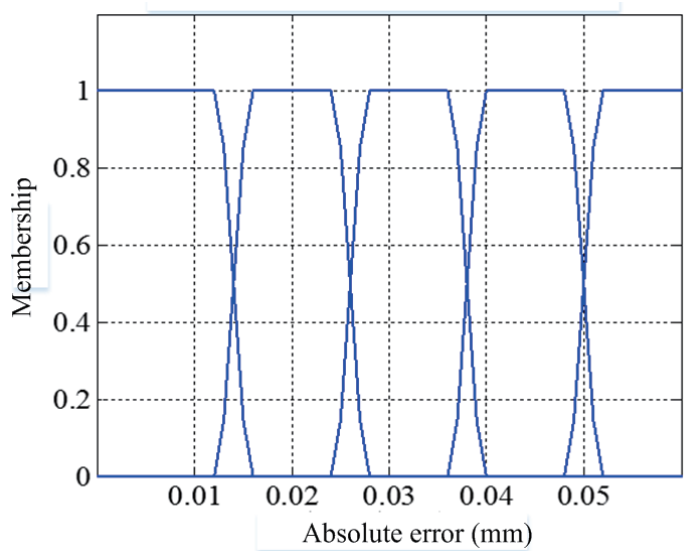

Fig. 13. (Color online) Membership functions of average contour error. 


$$
r_{i j}=\frac{x_{i j}-\min _{j}\left\{\mathrm{x}_{i j}\right\}}{\max _{j}\left\{\mathrm{x}_{i j}\right\}-\min _{j}\left\{\mathrm{x}_{i j}\right\}} .
$$

Then, the entropy of the $i$ th factor can be expressed as Eq. (7). The $f_{i j}$ in the equation represents the probability of the presentation in a certain state of the evaluation system. In addition, $f_{i j}=r_{i j} / \sum_{j=1}^{n} r_{i j}$.

$$
H_{i}=-k \sum_{j=1}^{n} f_{i j} \ln f_{i j}, i=1,2, \cdots, m
$$

After the entropy of factor $i$ is defined, the weight of factor $i$ can be expressed as Eq. (10). In addition, $0 \leq w_{i} \leq 1, \sum_{i=1}^{m} w_{i}=1$.

$$
w_{i}=\frac{1-H_{i}}{m-\sum_{i=1}^{m} H_{i}}
$$

For example, the weights of the dynamic parameters of the $Y$-axis are calculated using the simulation results as shown in Table 10. In addition, the weights of the affected zones of the $Y$-axis position gain $K_{p p}$ are shown in Table 11 .

When the membership functions between the layers are constructed and the weights of the factors in each layer are calculated, they should be aggregated together to calculate the final membership vector to obtain the final evaluation result of the machine tool. The expression of the aggregation model is given by

$$
x_{j}=\min \left(1, \sum_{i=1}^{m} w_{i} \times x_{i j}\right), j=1,2, \cdots, n .
$$

\subsection{Evaluation of machine tool dynamic accuracy}

The evaluation of machine tool dynamic accuracy involves two steps. The first step is to calculate the evaluation vector of the machine tool dynamic accuracy. It can be regarded as a positive evaluation process. The second step is to carry out the error cause identification of

Table 10

Weights of dynamic factors of $Y$-axis.

\begin{tabular}{lcccc}
\hline Dynamic factors & $K_{p p}$ & Backlash & Acceleration & Jerk \\
\hline Weights & 0.3948 & 0.2820 & 0.1763 & 0.1469 \\
\hline
\end{tabular}

Table 11

Weights of $K_{p p}$ of $Y$-axis.

\begin{tabular}{lcccc}
\hline Affected zones & C1 & C2 & E1 & E2 \\
\hline Weights & 0.2235 & 0.1863 & 0.3443 & 0.2459 \\
\hline
\end{tabular}


the machine tool dynamic accuracy. This step can be regarded as a reverse evaluation process. The final goal is to improve the machine tool dynamic accuracy by adjusting the key affecting factors.

(1) Calculation of evaluation vector

The evaluation of the machine tool dynamic performance by CE is a process of integrating and delivering various data. The flow chart of the evaluation process is shown in Fig. 14. The evaluation process in each layer consists of the calculation of the membership vectors and the weights of the factors mentioned in Sect. 4.1. By transferring the evaluation results from the bottom layer to the top layer, the final evaluation vector can be obtained. The evaluation vector is a description of the machine tool dynamic accuracy, which contains five factors that correspond to the accuracy level. The larger the preceding factors in the vector, the higher the machine tool dynamic accuracy.

(2) Error cause identification

If the effects of the factors in each layer on the contour error are different, the error cause identification of machine tool dynamic accuracy can be carried out. ${ }^{(45,46)}$ The error cause identification is similar to the evaluation, i.e., the final result is derived from the results of each layer of the evaluation model. The specific process is shown in Fig. 15. The level of each axis can be deduced using the evaluation vector of machine tool dynamic accuracy. Next, comparisons are made by combining the weight and level of each axis to determine the axis with the worst performance. Similarly, the dynamic parameter of this axis with the worst effects can be determined. The final result of the error cause identification is that the dynamic parameters of certain axes must be adjusted. Moreover, the parameters will be sorted according to the probability of causing the error.

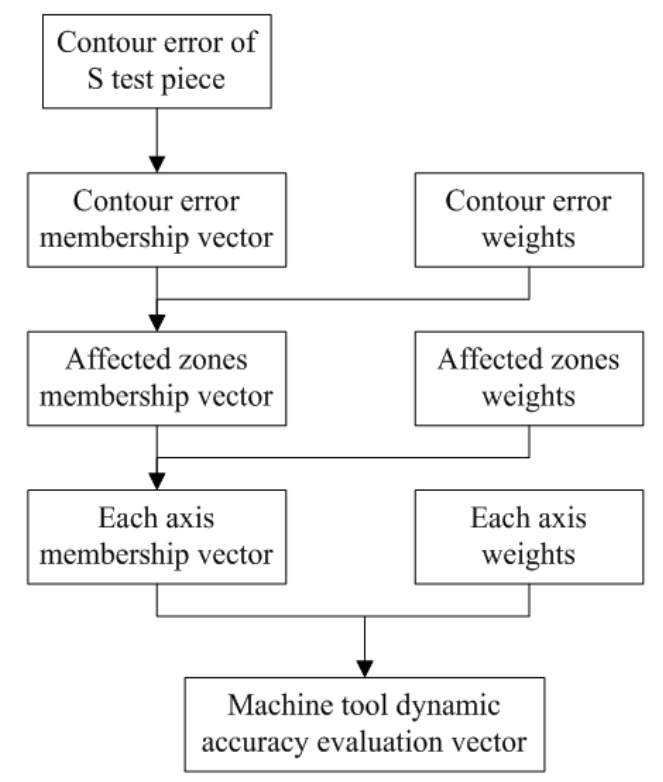

Fig. 14. Machine tool dynamic accuracy evaluation. 


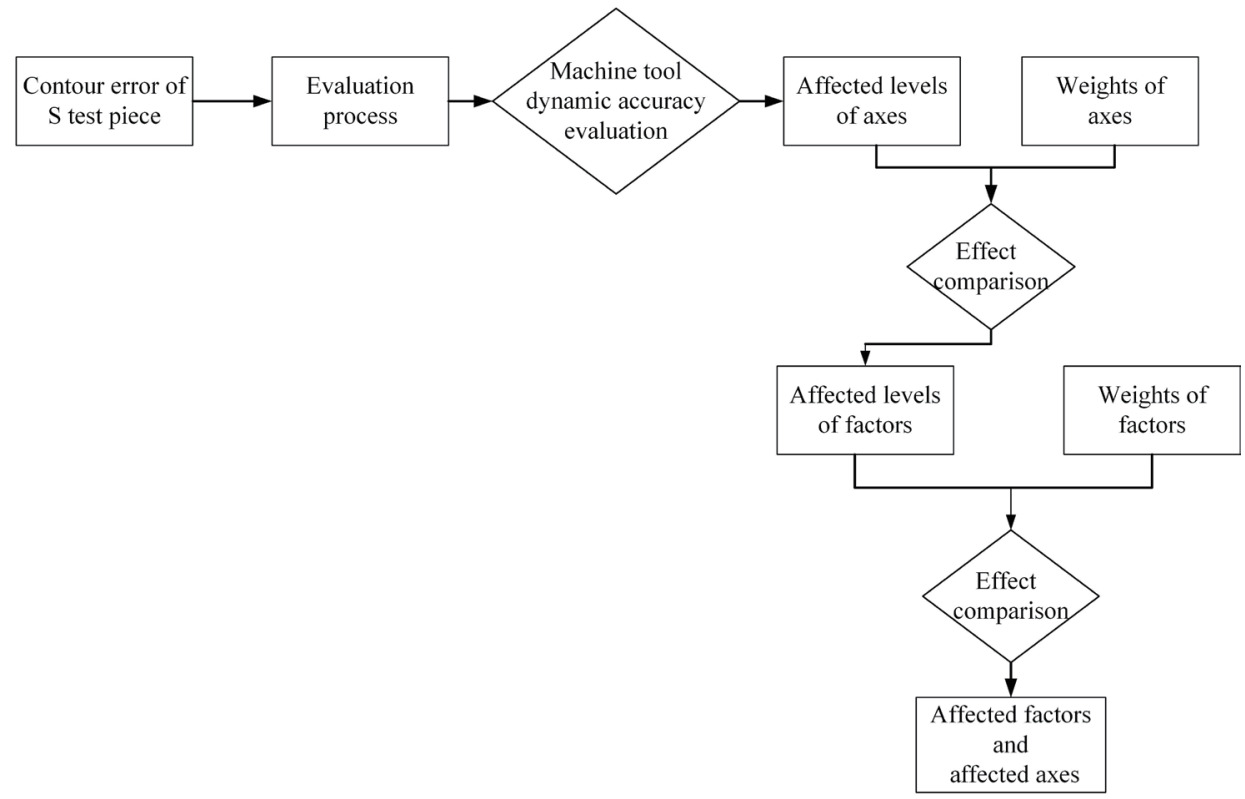

Fig. 15. Error cause identification of machine tool dynamic accuracy.

\section{Experiment Validation}

In this section, two experiments that were conducted are described. Because the effectiveness of the machine tool dynamic accuracy evaluation is dependent on the simulation results, the first experiment was to validate the relationship constructed in Sect. 3.2. The second experiment was to test if the adjustment of the dynamic parameters obtained through the error cause identification is helpful for the improvement of the machine tool dynamic accuracy. Thus, two machine tools were needed in the experiments. Two THM63100IV five-axis CNC machining centers named machine tools A and B are adopted in this paper. Before the cutting of the $\mathrm{S}$ test piece, the geometric precisions of the machine tools were both measured and then compensated. After the geometric precisions were tested and qualified, the $\mathrm{S}$ test piece was ready to be cut. The cutting parameters of the $\mathrm{S}$ test piece are listed in Table 12.

The contour error of the $\mathrm{S}$ test piece was measured using the coordinate measuring machine. A total of 50 positions were measured for one side surface. The 50 measuring points of a side surface are shown in Fig. 16. The actual cutting and measuring processes for the $\mathrm{S}$ test piece are shown in Fig. 17.

(a) Validation of simulation model

In Fig. 10, when the gains of the position control loops of the $X$-, $Y$-, $A$-, and $B$-axes are set different from those of the other axes, the corresponding affected zones are clearly different. Thus, five $\mathrm{S}$ test pieces were cut to see if the actual results match the simulation ones. One $\mathrm{S}$ test piece was cut under the initial state of the machine tool. The other four S test pieces were cut under the corresponding simulation conditions. Then, the actual change in contour error was compared with the simulation results. Machine tool A was used in this experiment. Before the cutting of the $\mathrm{S}$ test pieces, the dynamic accuracy of machine tool A was confirmed 
Table 12

Cutting parameters of S test piece.

\begin{tabular}{cccc}
\hline Spindle speed $(\mathrm{rpm})$ & Feed rate $(\mathrm{mm} / \mathrm{min})$ & Tool diameter $(\mathrm{mm})$ & Blank material \\
\hline 6000 & 800 & 20 & Aluminium alloy 7050-T7451 \\
\hline
\end{tabular}

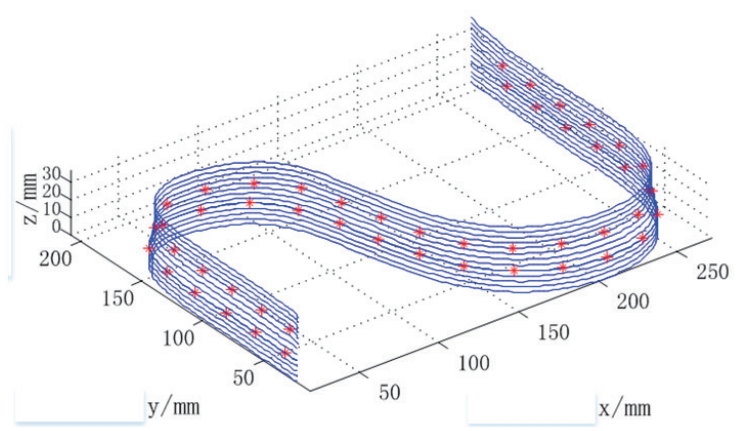

Fig. 16. (Color online) Measuring points on surface A.

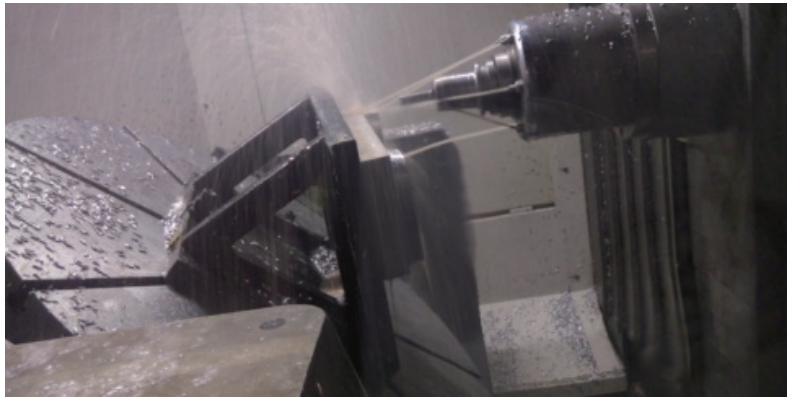

(a)

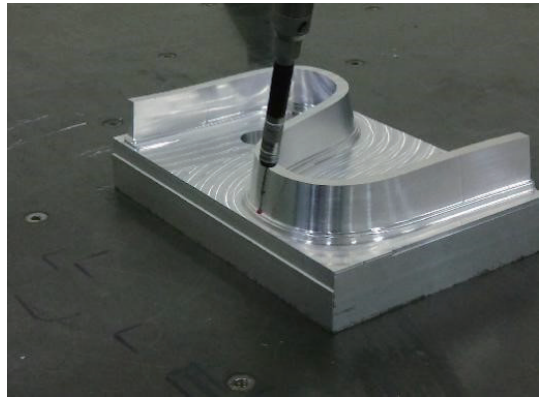

(b)

Fig. 17. (Color online) Cutting and measuring processes for $\mathrm{S}$ test piece. (a) Cutting process. (b) Measuring process.

to be sufficient. In Siemens $840 \mathrm{D}$ systems, the parameter of the position control loop gain is MD32200. By adjusting this parameter on purpose in turn, the position control loop gain can be changed. The actual cutting results are listed in Fig. 18.

In Fig. 18, to better distinguish the affected zones, the symbols of the affected zones corresponding to the measurement positions are given, and the residual error is magnified 10 times. From Table 13, the contour error change trend and the affected zones of the dynamic parameters are confirmed to be consistent with the simulation results. Thus, the simulation model is validated to be reliable. Moreover, the construction of the relationship between the $\mathrm{S}$ test piece and the dynamic parameters is effective.

(b) Validation of the machine tool dynamic accuracy improvement

Machine tool B was applied in the second experiment. Different from that of machine tool A, the dynamic accuracy of machine tool B does not need to be sufficient because the machine tool dynamic accuracy is expected to be improved through the evaluation method proposed in this paper.

First, two $\mathrm{S}$ test pieces were cut using machine tool B to evaluate the dynamic accuracy. The contour errors of these S test pieces, marked No. 1 and No. 2, are shown in Fig. 19. The 


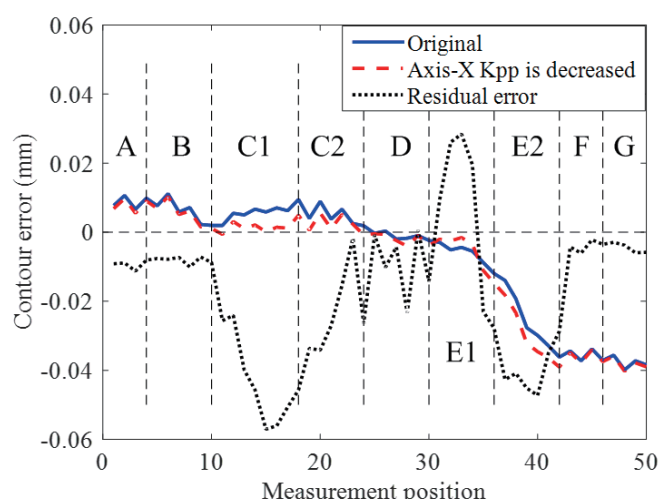

(a)

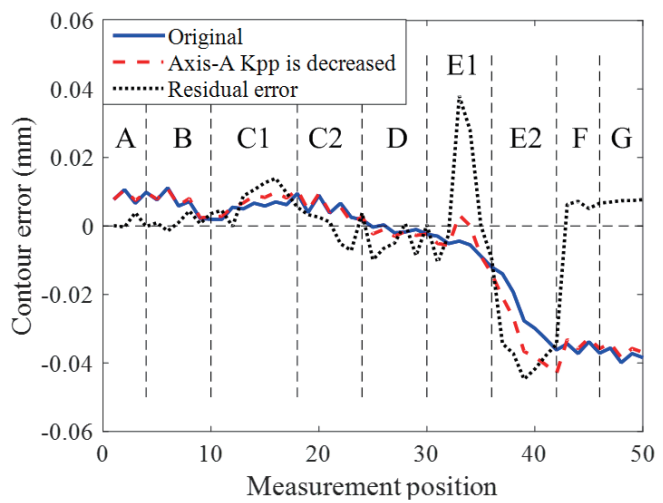

(c)

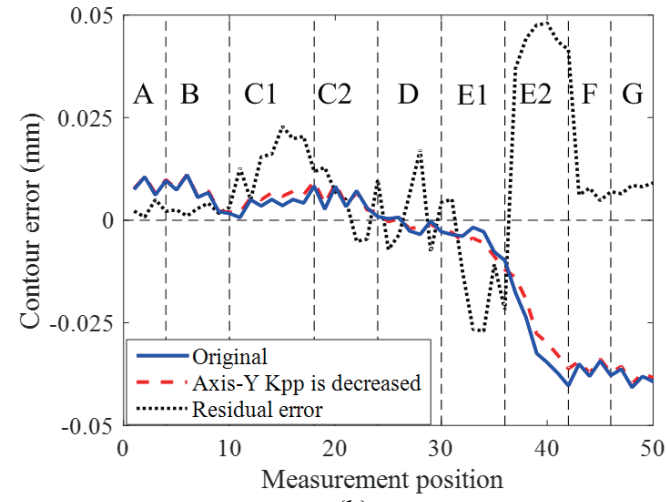

(b)

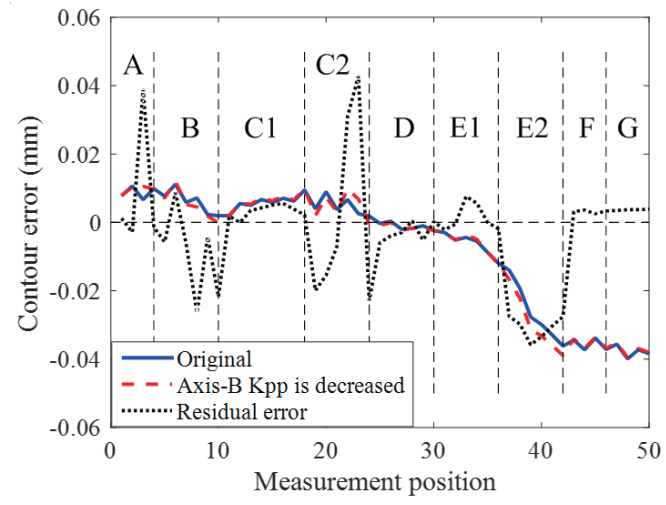

(d)

Fig. 18. (Color online) Actual contour error change of S test piece under different $K_{p p}$ sets. (a) The $K_{p p}$ of the $X$-axis is set different. (b) The $K_{p p}$ of the $Y$-axis is set different. (c) The $K_{p p}$ of the $A$-axis is set different. (d) The $K_{p p}$ of the $B$-axis is set different.

Table 13

Comparison between simulation and experiment results.

\begin{tabular}{lcc}
\hline Mode of parameter change & Affected zones in simulation & Affected zones in experiment \\
\hline$K_{p p}$ of $X$-axis is set different & C, E & C, E \\
$K_{p p}$ of $Y$-axis is set different & C, E & C, E \\
$K_{p p}$ of $A$-axis is set different & E & E \\
$K_{p p}$ of $B$-axis is set different & A, B, C2, E2 & A, B, C2, E2 \\
\hline
\end{tabular}

evaluation results of the machine tool dynamic accuracy can be obtained by evaluation with the inputs of the contour errors No. 1 and No. 2. The evaluation results are listed in Table 14.

From these results, it can be observed that the contour errors of these two test pieces maintain good repeatability. The absolute maximum contour errors both exceed $0.03 \mathrm{~mm}$. Note that, in the evaluation results, the evaluation vectors are given. As described in Sect. 4.2, the evaluation vector is a description of the machine tool dynamic accuracy. The resemblance of the evaluation vectors also explains the good repeatability of the cutting of the $\mathrm{S}$ test pieces. Then, on the basis of the evaluation vectors, the error cause identification was carried out. Through the error cause identification, the output dynamic parameters sorted by probability that must be adjusted are the $K_{p p}$ of the $X$-axis, the $K_{p p}$ of the $Y$-axis, the backlash of the $A$-axis, and the acceleration of the $A$-axis. Thus, the $K_{p p}$ 's of the $X$ - and $Y$-axes were selected to be adjusted 


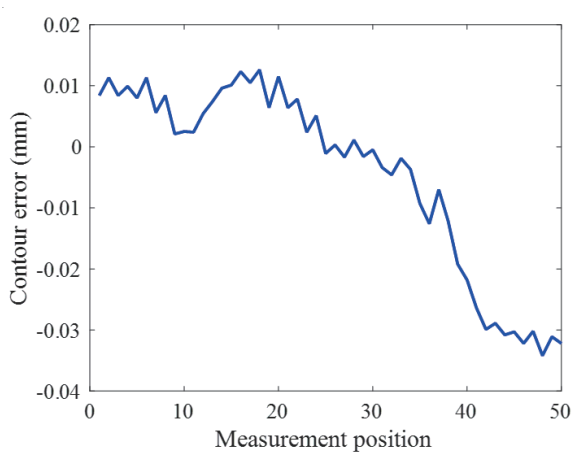

(a)

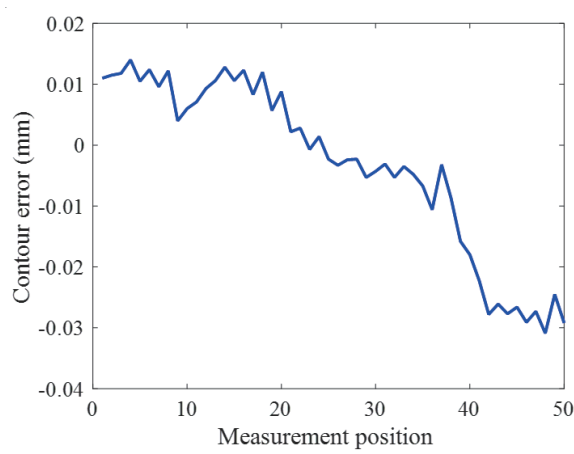

(b)

Fig. 19. (Color online) Contour errors of $\mathrm{S}$ test pieces with adjustment. (a) Contour error No. 1. (b) Contour error No. 2.

Table 14

Results of evaluation without adjustment.

\begin{tabular}{lccc}
\hline S test piece & Evaluation vector & $\begin{array}{c}\text { Absolute average } \\
\text { contour error }(\mathrm{mm})\end{array}$ & $\begin{array}{c}\text { Absolute maximum } \\
\text { contour error }(\mathrm{mm})\end{array}$ \\
\hline No. 1 & {$[0.0941,0.5702,0.2221,0.1136,0]$} & 0.0119 & 0.0342 \\
No. 2 & {$[0.0722,0.6187,0.2398,0.0693,0]$} & 0.0116 & 0.0309 \\
\hline
\end{tabular}

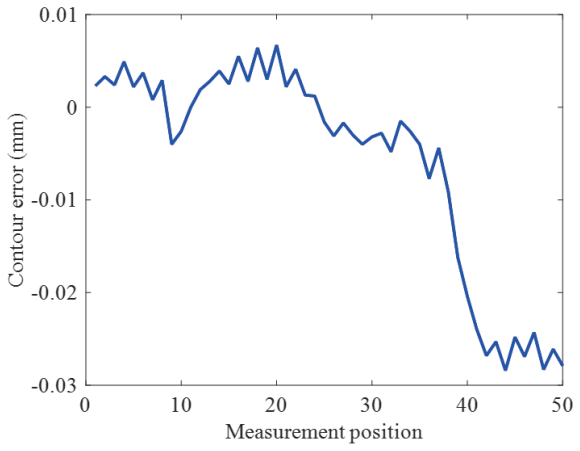

(a)

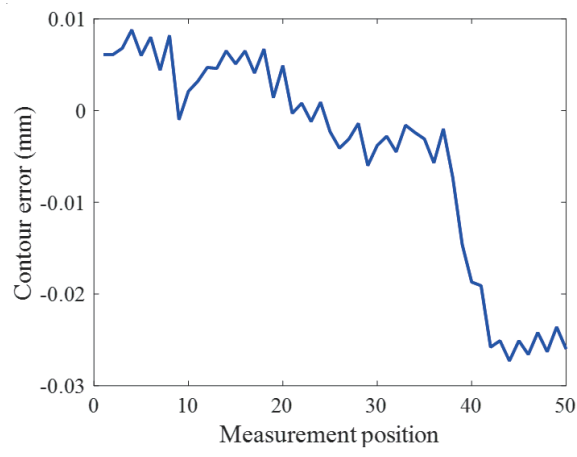

(b)

Fig. 20. (Color online) Contour errors of S test pieces with adjustment. (a) Contour error No. 3. (b) Contour error No. 4.

Table 15

Results of evaluation with adjustment.

\begin{tabular}{lccc}
\hline S test piece & Evaluation vector & $\begin{array}{c}\text { Absolute average } \\
\text { contour error }(\mathrm{mm})\end{array}$ & $\begin{array}{c}\text { Absolute maximum } \\
\text { contour error }(\mathrm{mm})\end{array}$ \\
\hline No. 3 & {$[0.4017,0.3596,0.2349,0.0038,0]$} & 0.0085 & 0.0284 \\
No. 4 & {$[0.3839,0.3682,0.2194,0.0285,0]$} & 0.0088 & 0.0273 \\
\hline
\end{tabular}

to see if the adjustment will be helpful for improving the machine tool dynamic accuracy. The $K_{p p}$ 's of the $X$ - and $Y$-axes were adjusted by improving the dynamic response and positioning accuracy. The specific adjustment process was omitted. After the adjustment, another two $\mathrm{S}$ test pieces were cut and their contour errors were marked No. 3 and No 4. The contour errors with the dynamic accuracy improvement are shown in Fig. 20. The evaluation results are listed in Table 15. 
From these results, it was observed that the contour errors of the $\mathrm{S}$ test pieces have decreased compared with those without adjustment. The absolute average contour error of the second group of two $\mathrm{S}$ test pieces is $0.0087 \mathrm{~mm}$, compared with that of the first group of two test pieces of $0.0118 \mathrm{~mm}$. The contour errors were decreased by about $26 \%$, which proved that the machine tool dynamic accuracy has been improved. Moreover, according to the description of the evaluation vector in Sect. 4.2, the comparison of the evaluation vectors in Table 15 with those in Table 14 can also validate the improvement of the machine tool dynamic accuracy.

\section{Conclusion}

In this paper, a new method of evaluating the dynamic accuracy of a five-axis machine tool is proposed. The evaluation method is based on the combination of an S test piece and a CE system. The $\mathrm{S}$ test piece and cone frustum were compared, and the $\mathrm{S}$ test piece was selected to carry out the evaluation because of its ability to reflect the change in dynamic accuracy through different surface locations. Through the construction of the kinematic and servo system models, the effects of various dynamic factors on the contour error of the $S$ test piece were analyzed. The CE system was adopted to evaluate the dynamic accuracy of the five-axis machine tool on the basis of the relationship between the dynamic factors and their corresponding affected zones. The final goal of the evaluation was to improve the dynamic accuracy of the five-axis machine tool by adjusting the error cause identified through the evaluation. Two experiments were conducted in the final part to validate the effectiveness of the evaluation method. The first experiment validated the reliability of the simulation model. The second experiment validated the effectiveness of the adjustment of the dynamic factors identified through the evaluation method. For further study, with the accumulation of data from actual cuttings of the S test piece, the weights in the $\mathrm{CE}$ model can be constantly optimized to improve the accuracy of the evaluation. In addition, the $\mathrm{S}$ test piece can be replaced by some new test pieces, making the evaluation more accurate.

\section{Acknowledgments}

This work was supported by the National Natural Science Foundation of China (61603076) and the National Defense Pre-Research Foundation of China (1126170104A, 1126180204B, $1126190402 \mathrm{~A}$, and 11126190508A).

\section{References}

1 L. Andolfatto, S. Lavernhe, and J. R. R Mayer: Int. J. Mach. Tools Manuf. 51 (2011) 787. https://doi. org/10.1016/j.ijmachtools.2011.07.002

2 G. Zhang, R. Ouyang, and B. Lu: CIRP Ann. 37 (1988) 515. https://doi.org/10.1016/S0007-8506(07)61690-4

3 G. Chen, J. Yuan, and J. Ni: Int. J. Mach. Tools Manuf. 41 (2001) 149. https://doi.org/10.1016/S08906955(00)00049-3

4 S. Wang and K. Ehmann: Int. J. Mach. Tools. Manuf. 39 (1999) 1485. https://doi.org/10.1016/S08906955(98)00070-4

5 J. Li, F. Xie, and X. Liu: Int. J. Adv. Manuf. Technol. 87 (2016) 1. https://doi.org/10.1007/s00170-016-8580-x 
6 J. M. Linares, J. Chaves-Jacob, and H. Schwenke: Precis. Eng. 38 (2014) 578. https://doi.org/10.1016/ j.precisioneng.2014.02.008

7 M. Camboulives, C. Lartigue, and P. Bourdet: Precis. Eng. 44 (2016) 163. https://doi.org/10.1016/ j.precisioneng.2015.11.005

8 S. Aguado, D. Samper, and J. Santolaria: Int. J. Mach. Tools. Manuf. 53 (2012) 160. https://doi.org/10.1016/ j.ijmachtools.2011.11.004

9 S. Aguado, D. Samper, and J. Santolaria: Meas. Sci. Technol. 23 (2012) 207. https://doi.org/10.1088/09570233/23/6/065003

10 M. Tsutsumi and A. Saito: Int. J. Mach. Tools Manuf. 43 (2003) 771. https://doi.org/10.1016/s08906955(03)00053-1

11 X. Jiang and R. J. Cripps: Int. J. Mach. Tools Manuf. 89 (2015) 151. https://doi.org/10.1016/ j.ijmachtools.2014.10.010

12 S. Xiang and Y. Altintas: Int. J. Mach. Tools Manuf. 101 (2016) 65. https://doi.org/10.1016/ j.ijmachtools.2015.11.006

13 S. Ibaraki, C. Oyama, and H. Otsubo: Int. J. Mach. Tools Manuf. 51 (2011) 190. https://doi.org/10.1016/ j.ijmachtools.2010.11.011

14 C. Hong, S. Ibaraki, and C. Oyama: Int. J. Mach. Tools Manuf. 59 (2012) 24. https://doi.org/10.1016/ j.ijmachtools.2012.03.004

15 C. Hong and S. Ibaraki: Precis. Eng. 37 (2013) 159. https://doi.org/10.1016/j.precisioneng.2012.07.012

16 AIA/NAS NAS 979: Uniform Cutting Tests-NAS Series, Metal Cutting Equipment Specifications Rev. 1 (1969) 34-37.

17 ISO/DIS 10791-7: Test Conditions for Machining Centres - Part 7: Accuracy of Finished Test Piece (2014) 31.

18 T. Matsushita, T. Oki, and A. Matsubara: Precis. Eng. 74 (2008) 632. https://doi.org/10.2493/jjspe.74.632

19 C. Hong, S. Ibaraki, and A. Matsubara: Precis. Eng. 35 (2011) 1. https://doi.org/10.1016/j.precisioneng.2010.09.004

20 K. Kiotoshi, M. Tsutsumi, and T. Saiki: 2010 JSPE Autumn Conf. (JSPE, 2010) 303-304. https://doi. org/10.11522/pscjspe.2010A.0.303.0

21 S. Ibaraki, M. Sawada, and A. Matsubara: Precis. Eng. 34 (2010) 387. https://doi.org/10.1016/ j.precisioneng.2009.09.007

22 S. Ibaraki and Y. Ota: Proc. CIRP. 14 (2014) 323. https://doi.org/10.1016/j.procir.2014.03.109

23 W. Wang, Z. Jiang, and W. Tao: Int. J. Adv. Manuf. Technol. 79 (2015) 729. https://doi.org/10.1007/s00170-0156870-3

24 W. Wang, Z. Jiang, and Q. Li: Int. J. Adv. Manuf. Technol. 79 (2015) 739. https://doi.org/10.1007/s00170-0156869-9

25 C. Wu, J. Fan, and Q. Wang: Int. J. Mach. Tools. Manuf. 124 (2018) 80. https://doi.org/10.1016/ j.ijmachtools.2017.07.008

26 L. Zhong, Q. Bi, and N. Huang: Int. J. Mach. Tools. Manuf. 125 (2018) 20. https://doi.org/10.1016/ j.ijmachtools.2017.11.003

27 A. N. Poo, J. G. Bollinger, and G. W. Younkin: IEEE Trans. Ind. Appl. 8 (1972) 477. https://doi.org/10.1109/ TIA.1972.349839

28 R. Ramesh, M. Mannan, and A. Poo: Int. J. Mach. Tools. Manuf. 45 (2005) 301. https://doi.org/10.1016/ j.ijmachtools.2004.08.008

29 C. Yang, X. Wang, L. Cheng, and H. Ma: IEEE. Trans. Cybern. 47 (2017) 3148. https://doi.org/10.1109/ TCYB.2016.2573837

30 C. Yang, G. Peng, L. Cheng, J. Na, and Z. Li: IEEE Trans. Syst. Man Cybern. Part A Syst. Humans (in press). https://doi.org/10.1109/TSMC.2019.2920870

31 G. Peng, C. Yang, W. He, and C. L. P. Chen: IEEE. Trans. Ind. Electron. 99 (2019) 1. https://doi.org/10.1109/ TIE.2019.2912781

32 C. Yang, J. Luo, Y. Pan, Z. Liu, and C. Y. Su: IEEE. Trans. Syst. Man Cybern. Part A Syst. Humans 48 (2018) 1759. https://doi.org/10.1109/TSMC.2017.2694020

33 B. Sencer and Y. Altintas: Croft E. J. Manuf. Sci. Eng. 131 (2009) 337. https://doi.org/10.1115./1.3123335

34 C. Yang, Y. Jiang, W. He, J. Na, Z. Li, and B. Xu: IEEE. Trans. Ind. Electron. 65 (2018) 8112. http://doi. org/10.1109/TIE.2018.2803773

35 J. Yang and Y. Altintas: Int. J. Mach. Tools. Manuf. 88 (2015) 9. https://doi.org/10.1016/j.ijmachtools.2014.08.004

36 F. Mojtaba, M. Ali, and K. Vali: J. Renewable Sustainable Energy Rev. 82 (2018) 415. https://doi.org/10.1016/ j.rser.2017.09.060

37 H. Wang, N. Jiang, and S. Shao: Cell. Biochem. Biophys. 72 (2015) 147. https://doi.org/10.1007/s12013-014$0426-2$ 
R. Yager and D. Filev: IEEE Trans. Syst. Man Cybern. 29 (1999) 141. https://doi.org/10.1007/978-3-642-179105 3

39 Z. Xu and Q. Da: Int. J. Intell. Syst. 18 (2010) 953. https://doi.org/10.1002/int.10127

40 Y. Wang and Y. Luo: Math. Comput. Model. 51 (2010) 1. https://doi.org/10.1016/j.mcm.2009.07.016

41 J. Wu, G. Yu, Y. Gao, and L. Wang: Mech. Mach. Theory 121 (2018) 430. https://doi.org/10.1016/ j.mechmachtheory.2017.10.023

42 J. Wu, J. Wang, and Z. You: Rob. Comput. Integr. Manuf. 26 (2010) 414. https://doi.org/10.1016/j.rcim.2010.03.013

43 J. Wu, J. Wang, L. Wang, and T. Li: Mech. Mach. Theory. 44 (2009) 835. https://doi.org/10.1016/ j.mechmachtheory.2008.04.002

44 K. Erkorkmaz and Y. Altintas. Int. J. Mach. Tools Manuf. 41 (2001) 1323. https://doi.org/10.1016/S08906955(01)00002-5

45 J. Liu, M. Fu, and F. Liu: IEEE Trans. Instrum. Meas. 67 (2018) 12. https://doi.org/10.1109/TIM.2017.2755918

46 J. Liu and F. Qu: IEEE Trans. Ind. Inform. 15 (2019) 3877. https://doi.org/10.1109/TII.2018.2885365

\section{About the Authors}

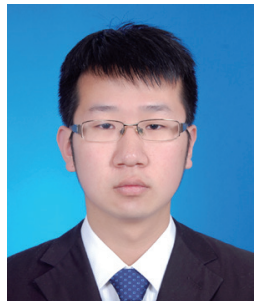

Shijie Song received his BS degree from Xi'an Shiyou University in 2016. Currently, he is pursuing his MS degree in mechatronics engineering at the University of Electronic Science and Technology of China, Chengdu, China. His research interests include parallel robotics.

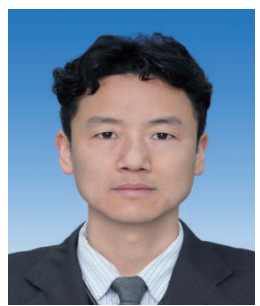

Xiaolin Dai received his $\mathrm{BS}, \mathrm{ME}$, and $\mathrm{PhD}$ degrees from the Harbin Institute of Technology, Harbin, in 1999, 2001, and 2009, respectively. Currently, he is a lecturer at the University of Electronic Science and Technology of China, Chengdu, China. His research interests include the analysis and control of parallel manipulators.

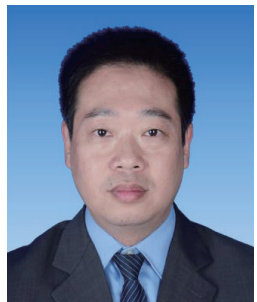

Xiaoning Li received his BS and ME degrees from the University of Electronic Science and Technology of China, Chengdu, in 1993 and 2002, respectively. Currently, he is a lecturer at the University of Electronic Science and Technology of China, Chengdu, China. His research interests include power electronics and power drives.

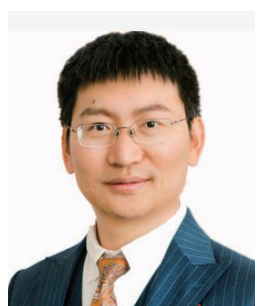

Dawei Gong received his $\mathrm{PhD}$ degree in control theory and control engineering from Northeastern University, Shenyang, China, in 2012. Currently, he is a lecturer at the University of Electronic Science and Technology of China, Chengdu, China. His current research interests include neural networks, complex networks, fuzzy modelling and control, optimization in process industries, and intelligent optimization algorithms. 